\author{
Marquette University \\ e-Publications@Marquette
}

2017

\title{
Active Site Structures of CYP11A1 in the Presence of Its Physiological Substrates and Alterations upon Binding of Adrenodoxin
}

Qianhong Zhu

Marquette University

Piotr J. Mak

Marquette University, piotr.mak@marquette.edu

Robert C. Tuckey

The University of Western Australia

James R. Kincaid

Marquette University, james.kincaid@marquette.edu

Follow this and additional works at: https://epublications.marquette.edu/chem_fac

Part of the Chemistry Commons

\section{Recommended Citation}

Zhu, Qianhong; Mak, Piotr J.; Tuckey, Robert C.; and Kincaid, James R., "Active Site Structures of CYP11A1 in the Presence of Its Physiological Substrates and Alterations upon Binding of Adrenodoxin" (2017).

Chemistry Faculty Research and Publications. 896.

https://epublications.marquette.edu/chem_fac/896 
Marquette University

\section{e-Publications@Marquette}

\section{Chemistry Faculty Research and Publications/College of Arts and Sciences}

This paper is NOT THE PUBLISHED VERSION; but the author's final, peer-reviewed manuscript. The published version may be accessed by following the link in th citation below.

Journal/Monograph, Vol. xx, No. x (xxxx): XX-XX. DOI. This article is @ [publisher] and permission has been granted for this version to appear in e-Publications@Marquette. [publisher] does not grant permission for this article to be further copied/distributed or hosted elsewhere without the express permission from [publisher].

\section{Active Site Structures of CYP11A1 in the Presence of Its Physiological Substrates and Alterations upon Binding of Adrenodoxin}

Qianhong Zhu

Department of Chemistry, Marquette University, Milwaukee, Wisconsin Piotr J. Mak Department of Chemistry, Marquette University, Milwaukee, Wisconsin Robert C. Tuckey School of Molecular Sciences, The University of Western Australia, Perth, WA 6009, Australia 
James R. Kincaid

Department of Chemistry, Marquette University, Milwaukee, Wisconsin

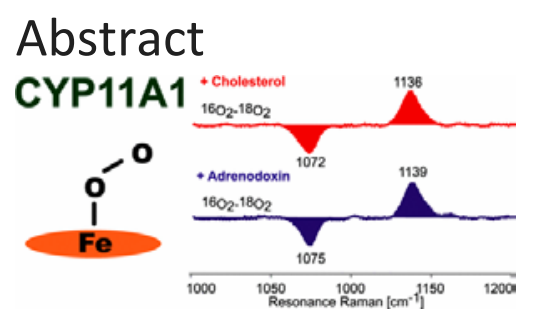

The rate-limiting step in the steroid synthesis pathway is catalyzed by CYP11A1 through three sequential reactions. The first two steps involve hydroxylations at positions 22 and 20 , generating $20(R), 22(R)$-dihydroxycholesterol $(20 R, 22 R$ - $\mathrm{DiOHCH})$, with the third stage leading to a C20-C22 bond cleavage, forming pregnenolone. This work provides detailed information about the active site structure of CYP11A1 in the resting state and substrate-bound ferric forms as well as the CO-ligated adducts. In addition, high-quality resonance Raman spectra are reported for the dioxygen complexes, providing new insight into the status of $\mathrm{Fe}-\mathrm{O}-\mathrm{O}$ fragments encountered during the enzymatic cycle. Results show that the three natural substrates of CYP11A1 have quite different effects on the active site structure, including variations of spin state populations, reorientations of heme peripheral groups, and, most importantly, substratemediated distortions of $\mathrm{Fe}-\mathrm{CO}$ and $\mathrm{Fe}-\mathrm{O}_{2}$ fragments, as revealed by telltale shifts of the observed vibrational modes. Specifically, the vibrational mode patterns observed for the $\mathrm{Fe}-\mathrm{O}-$ $\mathrm{O}$ fragments with the first and third substrates are consistent with $\mathrm{H}$-bonding interactions with the terminal oxygen, a structural feature that tends to promote $\mathrm{O}-\mathrm{O}$ bond cleavage to form the Compound I intermediate. Furthermore, such spectral data are acquired for complexes with the natural redox partner, adrenodoxin (Adx), revealing protein-protein-induced active site structural perturbations. While this work shows that Adx has an only weak effect on ferric and ferrous $\mathrm{CO}$ states, it has a relatively stronger impact on the $\mathrm{Fe}-\mathrm{O}-\mathrm{O}$ fragments of the functionally relevant oxy complexes.

Steroidogenic cytochromes P450 participate in the synthesis of steroid hormones that are essential for the maintenance of mammalian life.(1-3)Ultimately, all of these crucial hormones are generated from a common parent hormone, pregnenolone, which is derived from cholesterol in a complex process mediated by the multifunctional steroidogenic P450, CYP11A1. This inner mitochondrial membrane protein of the adrenal cortex is also known as cytochrome P450scc, a designation that refers to the catalyzed side cleavage reaction occurring between C20 and C22 (Figure 1). This rate-limiting step in the steroid synthesis pathway is catalyzed by CYP11A1 through three sequential steps illustrated in Figure 1, where the first two steps convert cholesterol $(\mathrm{CH})$ to $22(R)$-hydrocholesterol $(22 R-\mathrm{OHCH})$ and then to $20(R), 22(R)$ -

dihydroxycholesterol (20R,22R-DiOHCH), with the third stage leading to C20-C22 bond cleavage, thereby forming the key product, pregnenolone, and another small molecule, 4-methylpentanal (also called isocaproaldehyde).(4-7) 


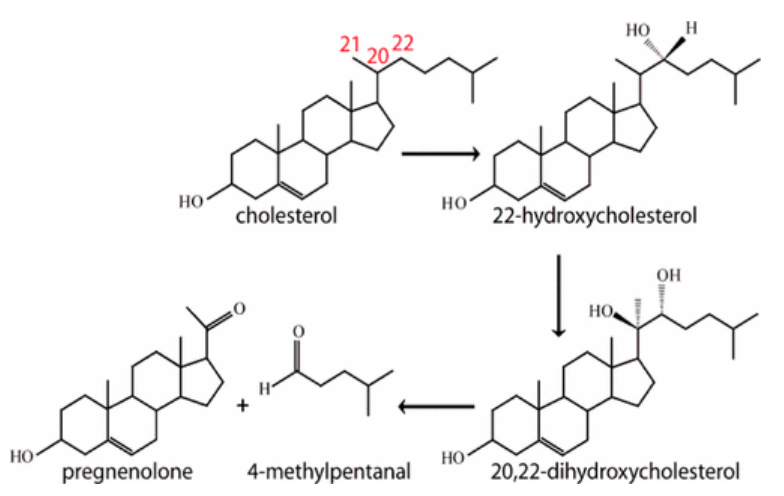

Figure 1. Structures of intermediate products encountered during the conversion of cholesterol to pregnenolone.

The well-established enzymatic cycle of cytochromes P450 is initiated by the substrate binding to a low-spin ferric "resting state", which disrupts a water cluster, displacing a bound axial water ligand, generating a high-spin ferric heme, with an elevated reduction potential that triggers acceptance of an electron. $(1,2)$ In the case of CYP11A1, the electron is provided by NADPHassociated adrenodoxin reductase (AdR) and delivered by an Fe-S cluster contained in adrenodoxin (Adx). $(8,9)$ Binding of molecular oxygen forms a dioxygen adduct, which is most properly formulated as a ferric superoxide species, $\mathrm{Fe}(\mathrm{III})-\left(\mathrm{O}^{-} \mathrm{O}^{-}\right) \cdot(10-13)$ Delivery of another electron from $\mathrm{Adx}$ then produces a ferric peroxo intermediate, $\mathrm{Fe}(\mathrm{III})-\left(\mathrm{O}-\mathrm{O}^{2-}\right)$. While special situations in which this ferric peroxo species can react directly with electron-deficient fragments of a given substrate do exist, $(14,15)$ generally, rapid sequential delivery of two heme-pocket protons first forms a transient hydroperoxo species that then undergoes efficient $\mathrm{O}-\mathrm{O}$ bond cleavage to generate an extremely potent oxidant, known as Compound I, which is most accurately formulated as a ferryl heme $\pi$ cation radical, i.e., [(porphyrin $\left.\left.{ }^{+\bullet}\right) \mathrm{Fe}(\mathrm{IV})=0\right] .(16-22)$

Interaction with natural or alternative reductases can alter the function and possibly the active site structure of the cytochrome P450.(1, 2, 14, 23-25)Adrenodoxin (Adx), which contains a [2Fe$2 \mathrm{~S}$ ] cluster, is generally believed to serve as an electron shuttle between a NADPH-containing enzyme, adrenodoxin reductase (AdR), and the active site of CYP11A1. $(9,23-25)$ It has been reported that the inherent reduction potential of substrate-bound CYP11A1 is -284 $\mathrm{mV}$ and that for $\mathrm{Adx}$ is $-273 \mathrm{mV}$, with protein-protein complex formation causing the reduction potential of Adx to undergo a small negative shift to $-291 \mathrm{mV}$, while that of CYP11A1 shifts to $-312 \mathrm{mV}$. $(26$, 27)The association of $A d x$ and CYP11A1 is postulated to arise from electrostatic interactions of charged surface residues of $A d x$ and CYP11A1,(9) with the recently reported crystal structure of the fusion protein between $\mathrm{Adx}$ and CYP11A1 revealing the presence of two salt bridges, consistent with this suggestion: Lys339 (CYP11A1)-Asp72 (Adx) and Lys343 (CYP11A1)-Asp76 (Adx)..$(28)$

Resonance Raman ( $\mathrm{rR}$ ) spectroscopy has been applied to study various heme proteins and enzymes for decades, $(29,30)$ permitting determinations of spin population change,(31) distortions of the heme as reflected in variations of the in-plane and out-of-plane macrocycle modes, $(29,30,32-37)$ and interactions of the vinyl and propionate groups on the heme periphery, as reflected in the behavior of the propionate and vinyl bending modes appearing in the low-frequency region and the vinyl group $\mathrm{v}(\mathrm{C}=\mathrm{C})$ stretching modes that are 
observed near $1600-1640 \mathrm{~cm}^{-1}$, both of which are sensitive to out-of-plane displacements of these groups with respect to the mean heme plane. $(32,38-41)$ Also, the technique is an especially powerful probe of the disposition of various endogenous and exogenous heme axial ligands. For example, the behavior of $\mathrm{v}(\mathrm{Fe}-\mathrm{C})$ and $\mathrm{v}(\mathrm{C}-\mathrm{O})$ for ferrous $\mathrm{CO}$ forms reveal detailed information about the polarity of the distal pocket.(42) Of special importance for this work is the fact that the $v(\mathrm{Fe}-\mathrm{O})$ and $v(\mathrm{O}-\mathrm{O})$ modes of the oxy form of cytochromes P450 are efficiently $\mathrm{rR}$ enhanced and provide telltale vibrational data that reflect subtle, but functionally important, $\mathrm{H}$ bonding interactions with distal side molecular fragments, including those of bound substrates.(42-44) Also important for the study presented here is the fact that $r R$ is able to probe the status of the key $v(\mathrm{Fe}-\mathrm{S})$ mode. $(32,45-48)$ Moreover, $\mathrm{rR}$ measurements can monitor the effects of redox partners on the heme active sites for all of the forms mentioned above.(48$\underline{50)}$

Early rR studies of CYP11A1 were reported mainly by Tsubaki et al.,(50-52) for the ferric and ferrous $\mathrm{CO}$ states, providing some valuable insight, but also leaving some unexplained issues of interpretation, which are further addressed here (vide infra). Most importantly, in the work presented here, we also expand the rR investigation of CYP11A1 to studies of the dioxygen complexes, ordinarily fleeting intermediates that must be prepared and stabilized under lowtemperature conditions. $(12,43,44)$ rR spectroscopy studies of such dioxy intermediates can reveal even subtle active site structural changes that significantly impact the disposition of crucial intermediates and influence alternative reaction pathways that may occur within these enzymatic cycles. $(43,44,53)$ For example, the $\mathrm{rR}$ technique can differentiate $\mathrm{H}$-bonding to the proximal oxygen $\left(\mathrm{Fe}-\mathrm{O}_{\mathrm{p}}\right)$ in an $\mathrm{Fe}-\mathrm{O}_{\mathrm{p}}-\mathrm{O}_{\mathrm{t}}$ fragment, leading to a lower $\mathrm{v}(\mathrm{Fe}-\mathrm{O})$ frequency, and $\mathrm{H}$ bonding to the terminal oxygen $\left(\mathrm{O}_{t}\right)$, which yields a relatively higher $v(\mathrm{Fe}-\mathrm{O})$ frequency. $(42-44$, 54) This is a quite important capability, because computational work on cytochromes P450 and NOS, $(55,56)$ as well as experimental work on NOS and truncated hemoglobins,(57-59) has indicated that hydrogen bonding to the proximal oxygen will stabilize the peroxo intermediate, thereby hindering cleavage of the $\mathrm{O}-\mathrm{O}$ bond, making it more likely that a (susceptible) substrate will be processed through the peroxo intermediate. $(53,55-59)$ On the other hand, hydrogen bonding to the terminal oxygen atom favors heterolytic cleavage of the $\mathrm{O}-\mathrm{O}$ bond, with the reaction inevitably proceeding though the Compound I intermediate.(16-22)

Our work provides detailed information about the active site structure of CYP11A1 in the resting state and substrate-bound ferric forms, the CO-ligated adducts, and the dioxy intermediates encountered in the enzymatic cycle. In addition, studies of the forms mentioned above in complex with the natural redox partner, Adx, interrogating protein-protein-induced active site structural perturbations are conducted. Specifically, the results show that the three natural substrates of CYP11A1 have quite different effects on the active site structure, including variations in spin state populations, reorientations of heme peripheral groups, and, most importantly, substrate-mediated distortions of the Fe-XY fragments of bound exogenous ligands, including $\mathrm{CO}$ and $\mathrm{O}_{2}$, as revealed by telltale shifts of the $v(X-Y), v(\mathrm{Fe}-\mathrm{X})$, and $\delta(\mathrm{Fe}-\mathrm{X}-\mathrm{Y})$ vibrational modes. On the other hand, most significantly, our results reveal that the vibrational mode patterns observed for the Fe-O-O fragments of the dioxygen adducts obtained with the first and third substrates are almost identical, being consistent with $\mathrm{H}$-bonding interactions to the terminal oxygen, a structural feature that tends to promote $\mathrm{O}-\mathrm{O}$ bond cleavage, leading to 
reactions mediated by a Compound I species, consistent with the conclusions of recent experimental work mentioned above.(60-62) Moreover, the effect of the binding of adrenodoxin to all three forms of CYP11A1 (ferric, ferrous CO, and oxygenated) was studied and shows that, although Adx has an only weak effect on ferric and ferrous $\mathrm{CO}$ states, it is seen for the first time that it has a relatively stronger impact on the Fe-O-O fragments of the functionally relevant oxy complexes.

\section{Materials and Methods}

\section{Materials}

The substrates, $\mathrm{CH}$ and 22R-OHCH, were purchased from Sigma-Aldrich (Milwaukee, WI), and $20 R, 22 R$-DiOHCH was purchased from Cayman Chemical (Ann Arbor, MI). 22R-OHCH and $20 R, 22 R$-DiOHCH were dissolved in an ethanol solution to make $25 \mathrm{mM}$ stock solutions.

\section{Protein Preparation}

Adrenodoxin (Adx) and CYP11A1 were purified from adrenal glands purchased from a local harvesting plant (Cargill, Milwaukee, WI). The purification processes were performed, as described in the Supporting Information, according to published procedures.(23, 63, 64)

\section{Sample Preparation for Resonance Raman}

CYP11A1 purified from the adrenal cortex by the procedure described above is recovered in a form that retains the natural substrate, cholesterol. The concentration of CYP11A1 for samples of the ferric and ferrous $\mathrm{CO}$ forms was $100 \mu \mathrm{M}$ in $100 \mathrm{mM}$ phosphate buffer (pH 7.4) containing $0.1 \mathrm{mM}$ dithiothreitol (DTT) and $0.1 \mathrm{mM}$ ethylenediaminetetraacetic acid (EDTA). The concentration of enzyme in the samples used for measurement of the $v(\mathrm{Fe}-\mathrm{S})$ stretching frequencies was $200 \mu \mathrm{M}$ in $10 \mathrm{mM}$ phosphate buffer (pH 7.4), $0.1 \mathrm{mM}$ DTT, and 0.1 mM EDTA. The Adx:CYP11A1 ratio was 1.2:1 for those samples containing Adx, noting that the samples containing the redox partner were incubated overnight at $4{ }^{\circ} \mathrm{C}$ to ensure full binding of $\mathrm{Adx}$. For the generation of CYP11A1 samples bound with the other substrates, advantage was taken of the fact that the binding affinity of the other two substrates, $22 R-O H C H$ and $20 R, 22 R-D i O H C H$, is much higher than that of cholesterol, enabling them to displace the cholesterol from the active site. Thus, these substrate-bound samples were made by adding, from an ethanol stock solution, a 3-5-fold molar excess of the hydroxycholesterol and incubating the samples overnight at $4{ }^{\circ} \mathrm{C}$ to ensure full exchange. $(12,65)$

With regard to the preparation of the various ligated forms, the ferrous $\mathrm{CO}$ adducts were made by addition of an excess amount of reducing agent, sodium dithionite $\left(\mathrm{Na}_{2} \mathrm{~S}_{2} \mathrm{O}_{4}\right)$, from a stock solution. A $100 \mu \mathrm{L}$ aliquot of $100 \mu \mathrm{M}$ CYP11A1 was placed in a nuclear magnetic resonance (NMR) tube (WG-5 Economy, Wilmad) and sealed with a rubber septum (Sigma-Aldrich). The tube was connected to a vacuum line with a needle connection. The sample was sparged three times by exchange with Ar gas and then exchanged twice with $\mathrm{CO}$ gas to ensure the sample was saturated with CO. A freshly prepared solution of sodium dithionite dissolved in an Ar-degassed buffer was added to the solution of CYP11A1. The ferric sample was reduced by addition of $\sim 2$ molar equivalents of a sodium dithionite solution $(8 \mu \mathrm{L})$. The ultraviolet spectrum was monitored over the next few minutes, showing a sharp band rising at $\sim 550 \mathrm{~nm}$ and a band 
disappearing at $\sim 645 \mathrm{~nm}$, which can be attributed to the HS ferric form; the solution was allowed to incubate for 15 min to ensure full conversion.

The oxygenated samples of CYP11A1 were prepared from the ferric samples in the following manner. A $100 \mu \mathrm{L}$ aliquot of a $200 \mu \mathrm{M}$ ferric sample was placed in a NMR tube and connected to a vacuum line tube adapter. On the vacuum line, the sample was alternately degassed and filled with Ar for three cycles. Addition of a freshly degassed sodium dithionite solution was made by using a gastight syringe through a rubber septum on the vacuum line system into the ferric sample. The NMR tube was gently tapped to allow the sample to mix well. In practice, the sample was titrated with the a sodium dithionite solution until the sharp band at $\sim 550 \mathrm{~nm}$ reached a maximum and the band at $\sim 645 \mathrm{~nm}$ had disappeared, as monitored by a special device (model CHEM2000-VIS, Ocean Optics Inc., Dunedin, FL) that is capable of recording absorption spectra from samples contained in NMR tubes (WG-5 Economy, Wilmad). Then oxygen was added to this ferrous sample by bubbling ${ }^{16} \mathrm{O}$ or ${ }^{18} \mathrm{O}$ gas, using a vortex mixer to gently agitate the sample. During the reduction and oxygenation steps, the sample tube was placed in an ice-cold bath at $0{ }^{\circ} \mathrm{C}$. The mixing time for oxygenation was different, depending on the substrate being studied; the samples containing the first two substrates, $\mathrm{CH}$ without $\mathrm{Adx}$ and $22 R-O H C H$ without $A d x$, were mixed for $30 \mathrm{~s}$, but the sample containing 20R,22R-DiOHCH without $A d x$ required mixing for $90 \mathrm{~s}$ to complete formation of the oxy form.(13) These relatively short mixing times were used, because under these conditions, mixing times longer than a couple of minutes gave rise to significant amounts of ferric forms. All samples were frozen by being immersed the the NMR tube in liquid nitrogen immediately after mixing. Some samples contained ethylene glycol or glycerol, and the spectral results obtained were the same as for protein with a solution of only buffer.

\section{Sample Preparation for Fourier Transform Infrared Spectroscopy (FTIR)}

Ferrous $\mathrm{CO}$ samples for FTIR measurement were made only for samples bound with $22 \mathrm{R}-\mathrm{OHCH}$ and $20 R, 22 R-\mathrm{DiOHCH}$, the value for the $\mathrm{CH}$-bound sample being available from the $\mathrm{r}$ data. The ferrous $\mathrm{CO}$ samples were made by adding a minimal amount of $\mathrm{Na}_{2} \mathrm{~S}_{2} \mathrm{O}_{4}$ powder to the $\mathrm{CO}$ saturated ferric sample prepared with $100 \mathrm{mM}$ phosphate buffer containing $0.1 \mathrm{mM}$ EDTA and $0.1 \mathrm{mM}$ DTT in a $2 \mathrm{~mL}$ glass vial sealed with a rubber septum and then incubating for $15 \mathrm{~min}$ at 4 ${ }^{\circ} \mathrm{C}$ to ensure full ligation. While addition of solid dithionite can cause changes in $\mathrm{pH}$ it is when added in excess, care was taken to add very small amounts; it is noted that the FTIR spectra for these and similarly prepared samples of $\mathrm{CO}$ adducts of other $\mathrm{P} 450$ s yielded spectra identical to those prepared by Tsubaki et al. and others. $(30,50-52)$ Then the ferrous CO sample was transferred as quickly as possible to the FTIR cell, which had already been flushed with $\mathrm{CO}$ gas. The concentrations of the protein for the FTIR samples were 200-300 $\mu \mathrm{M}$.

\section{Resonance Raman Measurements}

Ferric CYP11A1 samples were measured using the 406.7 and $356.4 \mathrm{~nm}$ excitation lines, while the $\mathrm{Fe}$ (II)-CO adducts were excited by the $441.6 \mathrm{~nm}$ line provided by a He-Cd laser (IK Series, Kimmon Koha Co., Ltd.). Multiple excitation lines, including the 356.4, 406.7, and $415.4 \mathrm{~nm}$ lines from a Kr${ }^{+}$laser (Coherent Innova Sabre Ion Laser) and $441.6 \mathrm{~nm}$ from the $\mathrm{He}-\mathrm{Cd}$ laser, were employed to try to enhance the $\mathrm{v}(\mathrm{O}-\mathrm{O})$ modes of the oxy samples, but $\mathrm{v}(\mathrm{O}-\mathrm{O})$ and $\mathrm{v}(\mathrm{Fe}-\mathrm{O})$ features with adequate signal-to-noise ratios were obtained only when using the $415.4 \mathrm{~nm}$ 
krypton lines or the $441.6 \mathrm{~nm}$ line from the He-Cd laser; it is noted that in many studies of dioxygen complexes of cytochromes P450, adequate enhancement of the internal modes of the Fe-O-O fragment is obtained with the $413 \mathrm{~nm}$ krypton line, but enhancement is slightly better with the $415.4 \mathrm{~nm}$ excitation used here. The $\mathrm{rR}$ spectra of all samples were collected using a Spex 1269 spectrometer equipped with Spec-10 LN-cooled detector (Princeton Instruments). The slit width was set at $150 \mu \mathrm{m}$, and a $1200 \mathrm{~g} / \mathrm{mm}$ grating was used; with this grating, the resultant spectral dispersion is $0.46 \mathrm{~cm}^{-1} /$ pixel.

The laser power for the ferric sample was adjusted to $\sim 10 \mathrm{~mW}$, whereas for the ferrous CO adducts and oxy samples, it was kept at $\sim 1 \mathrm{~mW}$ to minimize photodissociation. Moreover, to avoid laser-induced heating and protein degradation, the samples were contained in spinning NMR tubes. The $180^{\circ}$ backscattering geometry was used for all measurements, and the laser beam was focused onto the sample using a cylindrical lens, to form a line image to improve the collection efficiency at a given photon flux at the sample surface.(66) The ferric and ferrous CO samples were measured at room temperature, while the oxy samples were measured at $77 \mathrm{~K}$, employing an in-house designed immersion dewar, fitted with a NMR tube sample spinning device. Spectra were calibrated with fenchone (Sigma-Aldrich) and processed with Grams/32 Al software (Galactic Industries, Salem, NH).

\section{FTIR Measurements}

The infrared spectra were recorded using a 4020 Galaxy Series FTIR spectrometer from Matson Instruments. The IR OTTLE33 cell purchased from New Era, when equipped with a Teflon spacer with a $0.1 \mathrm{~mm}$ width placed between two $\mathrm{CaF}_{2}$ windows, requires only $60 \mu \mathrm{L}$ of sample for each measurement. The infrared spectrophotometer was run in single-beam mode. A spectrum was recorded with no sample cell present (i.e., air) to serve as a blank, and then six separate spectral traces of the ferric sample (each with 500 scans) were collected; the same procedure was used for collection of the ferrous-CO samples. The presented data are the difference spectra between the ferrous-CO and ferric samples; as mentioned above, the enzyme concentrations for these samples were 200-300 $\mu \mathrm{M}$.

\section{Results and Discussion}

While a large majority of cytochrome P450-mediated oxidations proceed through the Compound I intermediate arising from proton-assisted $\mathrm{O}-\mathrm{O}$ bond cleavage of the precursor ferric peroxo species, any conditions that effectively restrict protonation of the latter can facilitate its attack on susceptible bound substrates. $(55-57,67-70)$ Indeed, rR evidence of the presence of a $\mathrm{H}$-bonding interaction with the proximal oxygen of the $\left(\mathrm{Fe}-\mathrm{O}_{\mathrm{p}}-\mathrm{O}\right)$ fragment has recently been obtained, which supports this mechanism in the case of the $\mathrm{C}-\mathrm{C}$ bond cleavage reaction that occurs for 17-hydroxy-pregnenolone (17-OH PREG) processing by CYP17A1;(43, 53) on the other hand, a $\mathrm{H}$-bonding interaction with the terminal oxygen of the $\mathrm{Fe}-\mathrm{O}-$ $\mathrm{O}_{\mathrm{t}}$ fragment disfavors such a reaction, facilitating the multistep protonation and $\mathrm{O}-\mathrm{O}$ bond cleavage process that leads to formation of the Compound I species.(16-22) Indeed, rR data recently acquired for the dioxy complexes of CYP19 revealed spectral patterns consistent with $\mathrm{H}$-bonding to the distal oxygen atom of the $\mathrm{Fe}-\mathrm{O}-\mathrm{O}$ fragment, suggesting the likely involvement of Compound I mediation of the $\mathrm{C}-\mathrm{C}$ bond cleavage process that produces estrone 
product,(44) a conclusion that is in essential agreement with recent kinetic studies reported by Sligar and co-workers.(71)

Given that $r R$ spectroscopy provides an especially effective probe of these functionally important $\mathrm{H}$-bonding interactions with the $\mathrm{Fe}-\mathrm{O}-\mathrm{O}$ fragments of dioxy intermediates, it has herein been used to probe the dioxygen complexes obtained for CYP11A1 bound with each of its three natural substrates, $\mathrm{CH}, 22 \mathrm{R}-\mathrm{OHCH}$, and $20 R, 22 R-\mathrm{DiOHCH}$. However, before proceeding to a discussion of the new results obtained for the dioxygen adducts, to help clarify certain nebulous or incomplete results reported in previous studies,(50-52) we undertook additional rR studies to further define active site structural differences that exist for the ferric and ferrous CObound forms with each of the three physiologically relevant substrates. In addition, these studies provide further definition of the effects of adrenodoxin binding on the heme structure and its interactions with active site structural elements, including the Fe-S bond between the heme and the cysteine residue, a functionally crucial linkage that can be manipulated by slight structural alterations within the proximal heme pocket where adrenodoxin binding occurs.(2327)

\section{Ferric CYP11A1 and Its Interaction with Adrenodoxin}

Early rR studies of this enzyme were reported by Tsubaki et al.(50-52) for the ferric and ferrous $\mathrm{CO}$ states, providing valuable insight into its active site structure. However, the interpretations of some of these data were hampered by the presence of strong glycerol bands that overlap with some structure-sensitive heme vibrational modes. Compared with previous work, the data presented below were acquired from samples prepared under aqueous conditions without glycerol, ethylene glycol, or detergent, each of which was present in the previous study and complicated the interpretation by the presence of the additives' Raman bands in the lowfrequency and high-frequency regions; e.g., a high-intensity and wide glycerol band appearing at $\sim 1467 \mathrm{~cm}^{-1}$ complicates observation of the $v_{3}$ mode of the HS species, which occurs near 1484 $\mathrm{cm}^{-1},(50-52)$ an overlap that can directly lead to the wrong interpretation of the spin population.

Now turning our attention to the newly acquired data, we present the $\mathrm{rR}$ spectra of ferric CYP11A1 samples with $\mathrm{CH}, 22 \mathrm{R}-\mathrm{OHCH}$, and 20R,22R-DiOHCH substrates in high- and lowfrequency regions, as well as in the presence of the natural redox partner, adrenodoxin ( $\mathrm{Adx}$ ), in Figure 2. The high-frequency spectra were normalized to the $v_{4}$ mode at $1370 \mathrm{~cm}^{-1}$, and the low-frequency region was normalized to the $v_{7}$ mode near $674 \mathrm{~cm}^{-1}$; neither of these strong modes is included in these traces to allow a clearer presentation of the lower-intensity structure-sensitive heme modes. The assignments of the modes were performed according to the previous published data on cytochromes P450s and model compounds of $\mathrm{Ni}$ octaethylporphyrin. $(29,72)$ 


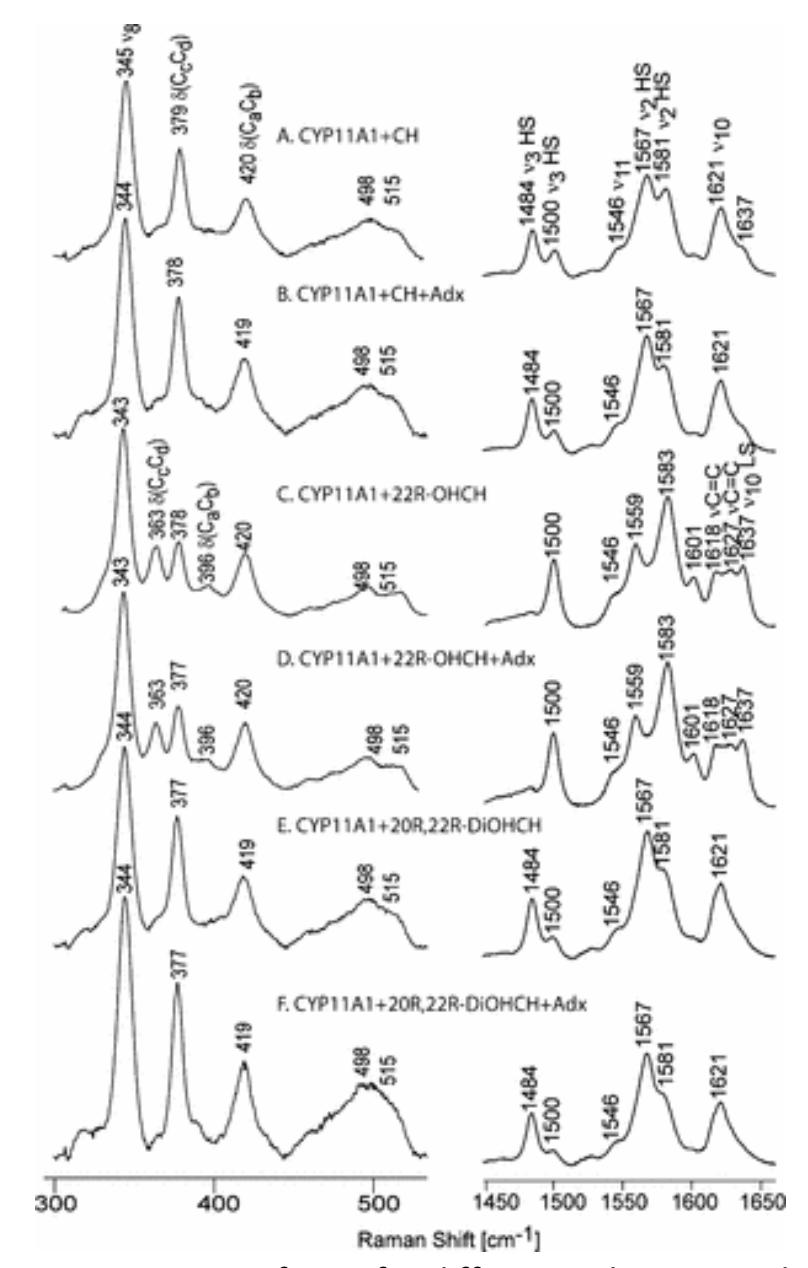

Figure 2. Ferric forms for different substrates in buffer comprising $100 \mathrm{mM}$ phosphate (pH 7.4), $0.1 \mathrm{mM}$ DTT, and $0.1 \mathrm{mM}$ EDTA. The excitation line was $406 \mathrm{~nm}$, and the acquisition time was 60 min for the low frequency and $30 \mathrm{~min}$ for the high frequency at room temperature.

\section{High-Frequency Region}

The spectra of cholesterol $(\mathrm{CH})$-bound samples (Figure 2A, right panel) show components associated with the high-spin (HS) and low-spin (LS) states. The population of the high-spin state is larger than that of the LS state as seen by the higher intensity of high-spin markers $v_{3}$ at 1484 $\mathrm{cm}^{-1}, \mathrm{v}_{2}$ at $1567 \mathrm{~cm}^{-1}$, and $\mathrm{v}_{10}$ at $\sim 1621 \mathrm{~cm}^{-1}$ as compared to the corresponding low-spin makers, which are seen at 1500,1581 , and $1637 \mathrm{~cm}^{-1}$, respectively. It is noted that the HS $v_{10}$ mode overlaps with the vinyl stretching modes that are seen more clearly in the spectrum of LS.(33) Binding of 22R-OHCH induces an almost complete low-spin state conversion, as seen by the presence of the dominant LS state markers $v_{3}$ at $1500 \mathrm{~cm}^{-1}, v_{2}$ at $\sim 1582 \mathrm{~cm}^{-1}$, and $v_{10}$ at $1637 \mathrm{~cm}^{-1}$. The absence of the HS $\mathrm{V}_{10}$ mode in this region (now appearing for the LS state at $1637 \mathrm{~cm}^{-1}$ ) reveals the existence of two vinyl stretching modes at 1618 and $1627 \mathrm{~cm}^{-1}$, the lower-frequency one usually being associated with the in-plane conformation of a vinyl group and the higher-frequency one being associated with the out-of-plane conformation. $(32,38)$ The fact that the $22 \mathrm{R}-\mathrm{OHCH}$ substrate does not induce high-spin conversion is not surprising, given the fact that the crystal structure of CYP11A1 with this substrate shows that there is a large amount of electron density between the $\mathrm{O}$ atom of the hydroxyl group attached to the position 
22 carbon of the substrate and the heme $\mathrm{Fe}$, with the distance between the $\mathrm{O}$ and Fe being only $2.56 \AA$, indicative of a covalent bond between the heme iron and substrate. $(28,73)$ This observation is entirely consistent with the $\mathrm{rR}$ data presented here and generally consistent with those previously published.(50-52) On the other hand, binding of 20R,22R-DiOHCH induces a mixture of spin states (76\% HS) similar to, but slightly larger, than that seen for the $\mathrm{CH}$-bound sample (63\% HS) (Figure 2E); i.e., interestingly, this diol-containing substrate does not coordinate to the heme. The stated spin state populations for all three enzyme-substrate complexes were calculated using previously published HS/LS cross section ratios for cytochromes P450.(31)

\section{Low-Frequency Region}

The low-frequency spectrum of the $\mathrm{CH}$-bound sample (Figure $2 \mathrm{~A}$, left panel) shows the presence of the propionate bending mode at $379 \mathrm{~cm}^{-1}$ and the vinyl bending mode at $420 \mathrm{~cm}^{-1}$. For the $22 \mathrm{R}-\mathrm{OHCH}$-bound sample, an additional propionate bending mode at $363 \mathrm{~cm}^{-1}$ is activated, a frequency that generally signals the presence of a propionate group experiencing a weaker $\mathrm{H}$ bonding interaction with active site fragments. $(32,41)$ Moreover, a small band appearing at 396 $\mathrm{cm}^{-1}$ was also enhanced and can be reasonably associated with weak activation of an in-plane vinyl bending mode. The presence of two vinyl bending modes associated with in-plane $\left(396 \mathrm{~cm}^{-}\right.$ $\left.{ }^{1}\right)$ and out-of-plane $\left(420 \mathrm{~cm}^{-1}\right)$ vinyl group conformations in the low-frequency region of the $r R$ spectrum of the $22 \mathrm{R}-\mathrm{OHCH}$-bound sample is indeed quite consistent with the two vinyl stretching frequencies observed in the high-frequency region, as discussed above (Figure $2 \mathrm{C}$ ). Again, the binding of the third substrate (Figure $2 \mathrm{E}$, left panel) shows a spectral pattern quite similar to that of the $\mathrm{CH}$-bound samples.

\section{Effect of Adrenodoxin on the Ferric State}

As can be seen from the slightly increased intensity of $v_{3}$ spin state markers at $\sim 1484 \mathrm{~cm}^{-1}$ from panels B, D, and F of Figure 2, for all three substrates, the addition of Adx to the samples of CYP11A1 causes only very small increases $(5-10 \%)$ in the high-spin population, as determined from the previously referenced procedure,(31) with the detailed data being found in Table S1. It was reported previously, using ultraviolet-visible and resonance Raman spectroscopies, that the redox partner, Adx, promotes formation of more high-spin component; e.g., for the $\mathrm{CH}$-bound form, it was reported that upon binding of Adx the HS population increased from only $~ 50 \%$ to complete transformation to HS.(50) While the results presented here did not show such large spin state changes, it has to be noted that the previous $\mathrm{rR}$ results were collected on samples that contained glycerol or propylene glycol, whose vibrational modes overlapped the HS state marker band at $\sim 1484 \mathrm{~cm}^{-1}$, making it difficult to properly determine the percentage of the $\mathrm{HS}$ component. $(50,51)$ It is emphasized that with the experimental conditions being used here, the $v_{3}$ marker band is quite isolated. In addition, studies we performed using the same experimental condition as previously described with proteins prepared in buffer containing $20 \%$ glycerol still gave no significant changes in the spin state when Adx was added (data not shown). The effect of adrenodoxin binding on the $r R$ spectra in the low-frequency region is also insignificant, as seen by the lack of changes in the pairs of traces $A$ and $B, C$ and $D$, and $E$ and $F$ (Figure 2, left panel). 


\section{Iron-Sulfur Linkage}

Obviously, the nature of the linkage between the heme prosthetic group and a given associated protein is quite important for dictating the reactivity patterns of the enzyme.(74-77) Indeed, the Fe-S linkage of cytochromes P450 and some related enzymes plays a key role in enabling these enzymes to mediate such remarkable chemical transformations under normal physiological conditions.(1-3) Fortunately, it has been well established that $r R$ spectroscopy, when employing a near-ultraviolet excitation wavelength (e.g., near 350-360 nm), is one of the most effective probes of the status of this key Fe-S fragment, providing an easily identifiable $v(\mathrm{Fe}-\mathrm{S})$ band in the low-frequency rR spectrum.(45-47) Specifically, the behavior of this mode can be documented to evaluate the linkage between the heme Fe and the endogenous cysteine thiolate ligand, the strength of which can be modulated by structural alterations within the proximal heme pocket, the most effective perturbations arising by interaction with natural redox partners such as Adx, which typically bind to the proximal side of the active site.

Several studies have consistently shown that the precise structures of substrates, all of which bind within the distal pocket of cytochromes P450, have little or no effect on the Fe-S linkage. $(46-48,78)$ However, we anticipate that interactions with redox partners can impact the status of the Fe-S linkage. $(46,48,79)$ Results of our work are shown in Figure 3 , where v(Fe-S) is observed at $347 \mathrm{~cm}^{-1}$ for CYP11A1 bound with $\mathrm{CH}$, with no detectable change being seen upon binding of $\mathrm{Adx}$. This is an unexpected result inasmuch as significant effects on the v(Fe-S) mode are commonly seen for these types of interactions; e.g., binding of putidaredoxin to P450cam caused a strengthening of the Fe-S bond, as witnessed by a shift in v(Fe-S) by $\sim 3 \mathrm{~cm}^{-1}$ to a higher frequency.(46) In addition, a differential effect on the Fe-S bond was seen for interactions of CYP2B4 with cytochrome $b_{5}$ versus CPR.(48) More recently, studies of nanodiscassociated CYP17 also provided evidence that binding of cytochrome $b_{5}$ induces a $3 \mathrm{~cm}^{-1}$ shift of the $v(\mathrm{Fe}-\mathrm{S})$ mode to a higher frequency.(79) 


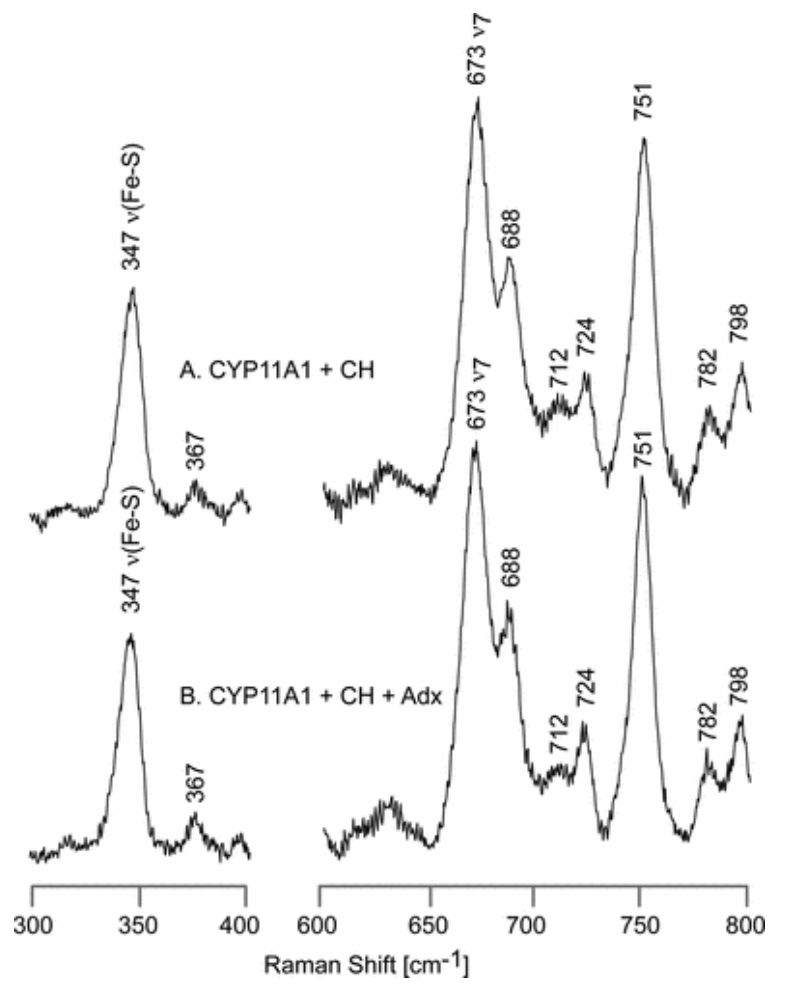

Figure 3. Low-frequency rR spectra of ferric cholesterol-bound CYP11A1 in $10 \mathrm{mM}$ phosphate buffer ( $\mathrm{pH}$ 7.4), $0.1 \mathrm{mM}$ DTT, and $0.1 \mathrm{mM}$ EDTA. The excitation line was $356.4 \mathrm{~nm}$, and the acquisition time was $60 \mathrm{~min}$ at room temperature.

\section{Ferrous-CO Adduct and Its Interaction with Different Substrates and}

\section{Adrenodoxin}

Resonance Raman spectroscopic interrogation of the ferrous $\mathrm{CO}$ adducts of heme proteins has long been established as an effective probe of proximal-pocket and especially distal-pocket active site structure. The internal modes of the Fe-C-O fragment report on the strength of the Fe-L linkage with the trans-axial proximal ligand and simultaneously reflect steric and polar interactions with distal-pocket residues, including those presented by the enzyme-bound substrate, $(42,80-82)$ the latter interaction being crucially important for cytochromes $\mathrm{P} 450$, such as the CYP11A1 being studied here. Basically, increases in the degree of $d \pi(\mathrm{Fe})$ to $\mathrm{CO}\left(\pi^{*}\right)$ backbonding in the $\mathrm{Fe}-\mathrm{C}-\mathrm{O}$ fragment, leading to increases in the positive polarity of the distal-pocket environment, strengthen the $\mathrm{Fe}-\mathrm{C}$ bond while simultaneously weakening the $\mathrm{C}-\mathrm{O}$ bond, resulting in a negative correlation between the $v(\mathrm{Fe}-\mathrm{C})$ and $\mathrm{v}(\mathrm{C}-\mathrm{O})$ vibrational modes. $(42,80-$ 82)

While rR spectroscopy has been applied previously to interrogate the active site of the CO adducts of CYP11A1 with various substrates, (50-52) one troubling issue occurred with the ferrous $\mathrm{CO}$ adducts, where it was reported that the $\mathrm{rR}$ spectrum of the $22 \mathrm{R}-\mathrm{OHCH}$-bound sample contained only one $\mathrm{v}(\mathrm{Fe}-\mathrm{C})$ stretching frequency, while the IR data clearly revealed the presence of two $\mathrm{v}(\mathrm{C}-\mathrm{O})$ stretching modes. The most reasonable explanation of this unexpected behavior is unintentional photodissociation of $\mathrm{CO}$ of one of the conformers during the Raman experiment. In our work, attempts are made to clarify the interpretation of the vibrational 
spectra of the ferric and ferrous $\mathrm{CO}$ adducts for all three physiologically important substrates and to further evaluate the effect of $\mathrm{Adx}$ binding on the $\mathrm{Fe}-\mathrm{C}-\mathrm{O}$ fragment of the $\mathrm{CO}$ adducts of CYP11A1.

The rR spectra acquired for the low-frequency region are shown in Figure 4.

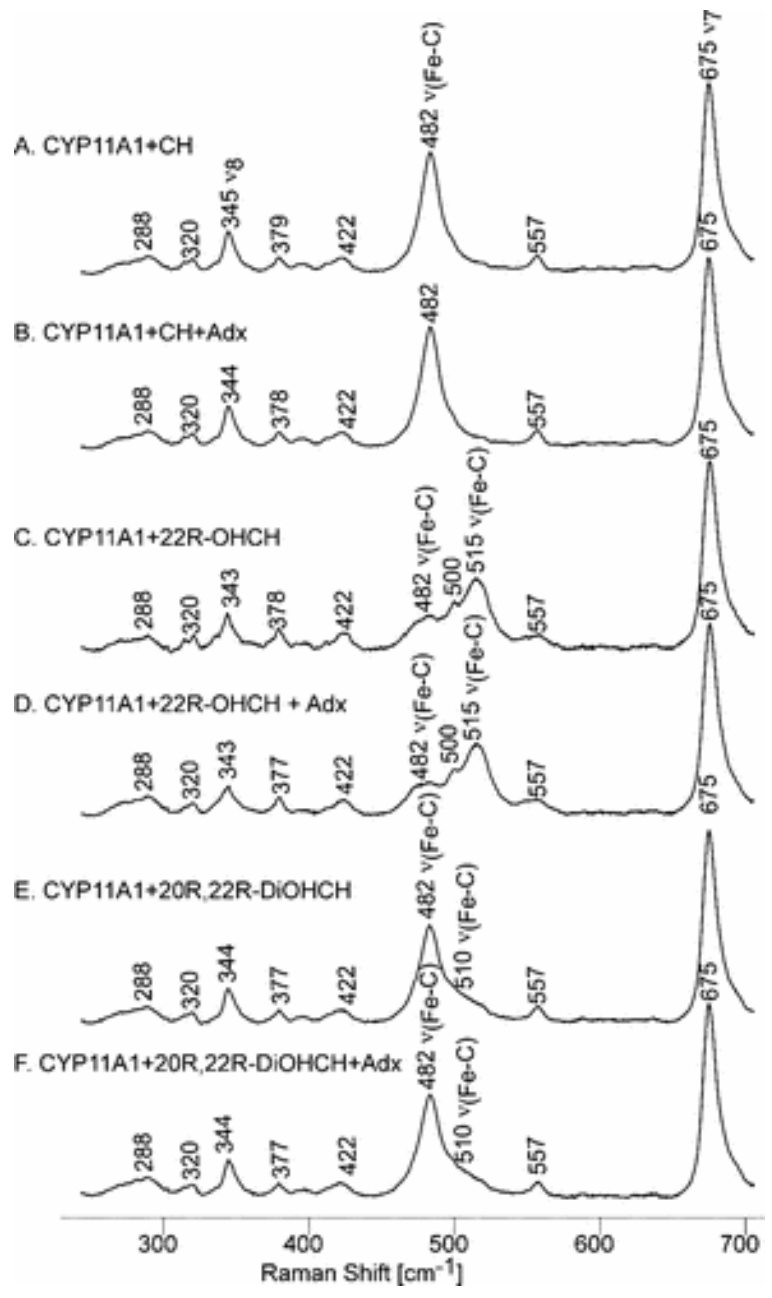

Figure 4. Low-frequency rR spectra for $\mathrm{CO}$ adducts of CYP11A1 with different substrates in 100 $\mathrm{mM}$ phosphate buffer (pH 7.4), $0.1 \mathrm{mM}$ DTT, and $0.1 \mathrm{mM}$ EDTA. The excitation line was 441.6 $\mathrm{nm}$, and the acquisition time was $60 \mathrm{~min}$ at room temperature.

The most obvious finding that is noted upon initial inspection of the data is that there are no observable effects of Adx binding upon the status of the Fe-C-O fragment. In similar studies reported previously by others, $(52)$ the changes in $\mathrm{Adx}$ binding were reported to be quite small (between 0 and $1.5 \mathrm{~cm}^{-1}$ ). However, the apparent existence of these small effects, along with the presence of some confusing results of those spectral studies, prompted us to reexamine this issue. For example, in those earlier studies, it was reported that in some cases, including the sample containing the $22 \mathrm{R}-\mathrm{OHCH}$, while two $\mathrm{v}(\mathrm{C}-\mathrm{O})$ modes could be observed by FTIR, only a single $v(\mathrm{Fe}-\mathrm{C})$ mode could be observed by $\mathrm{rR}$. As shown below, these confusing results can be readily explained by the occurrence of unintended photodissociation for the ferrous $\mathrm{CO}$ adducts by the $\mathrm{rR}$ laser excitation beam. 
Now, returning to consider the effects of different substrates on the $\mathrm{Fe}-\mathrm{C}-\mathrm{O}$ fragment, we find the sample bound with cholesterol, a substrate that presents no hydrophilic $\mathrm{R}-\mathrm{OH}$ fragments to the bound $\mathrm{CO}$ ligand, shows a clear and relatively sharp $\mathrm{v}(\mathrm{Fe}-\mathrm{C})$ mode appearing at $482 \mathrm{~cm}^{-1}$, a value in good agreement with the previous work, $(51)$ and the corresponding $v(C-O)$ being observed in the FTIR spectrum at $1952 \mathrm{~cm}^{-1}$, again a value in reasonably good agreement with that reported previously (i.e., $1954 \mathrm{~cm}^{-1}$ ).(51) In contrast to the relatively simple spectral signature displayed for the $\mathrm{CO}$ adduct of the $\mathrm{CH}$-bound enzyme, the $\mathrm{CO}$ adduct formed for the enzyme bound with the more polar substrate, $22 \mathrm{R}-\mathrm{OHCH}$, whose $\mathrm{C} 22-\mathrm{OH}$ fragment is apparently close enough to the iron binding site to have induced a LS spin state by direct interaction with the heme iron as evidenced in the $\mathrm{rR}$ data for the ferric state (Figure 2), gave three observed features appearing in the region where the $\mathrm{v}(\mathrm{Fe}-\mathrm{C})$ modes are expected to appear, i.e., at 482,500 , and $515 \mathrm{~cm}^{-1}$. To clarify the interpretation of the spectra acquired for the $22 R$-OHCH substrate, the $\mathrm{Fe}(\mathrm{II})-{ }^{12} \mathrm{C}^{16} \mathrm{O}$ and $\mathrm{Fe}(\mathrm{II})-{ }^{13} \mathrm{C}^{16} \mathrm{O}$ samples were made and measured with the results being shown in Figure 5 . It is clear that both 481 and $515 \mathrm{~cm}^{-1}$ bands seen in trace $A$ shifted down by $5 \mathrm{~cm}^{-1}$ in the spectra of the ${ }^{13} \mathrm{C}^{16} \mathrm{O}$ isotope, confirming their assignments to $\mathrm{v}(\mathrm{Fe}-\mathrm{C})$ modes. On the other hand, the feature observed at $500 \mathrm{~cm}^{-1}$ does not shift upon substitution with ${ }^{12} \mathrm{C}$ and/or ${ }^{13} \mathrm{C}$, securing its assignment to a heme mode. The assignment of the 481 and $515 \mathrm{~cm}^{-1}$ bands to two different $\mathrm{Fe}-\mathrm{C}-\mathrm{O}$ conformers is supported by observation two high-frequency $v(C-O)$ modes at 1952 and $1934 \mathrm{~cm}^{-1}$ in the FTIR spectrum, as shown in Figure 6 . In previously published work,(51) the appearance of only one band at a low frequency was reported for this complex, an observation that may be due to accidental photodissociation perhaps caused by either a high laser power $(\sim 5 \mathrm{~mW})$ or ineffective spinning during the measurement. Indeed, results of experiments to verify photosensitivity for this complex are shown in the bottom two traces of Figure 5, where it is seen that in the spectra acquired at high photon flux (traces $C$ and $D$ ), there is a strong and wide heme mode, with its expected insensitivity to the ${ }^{13} \mathrm{C}^{16} \mathrm{O}$ substitution that overlapped with the $\mathrm{v}(\mathrm{Fe}-\mathrm{C})$ modes. From previously published data, it was reported that only one $v\left(\mathrm{Fe}-\mathrm{C}\right.$ ) mode could be detected (at $479 \mathrm{~cm}^{-1}$ ) for the $22 \mathrm{R}-\mathrm{OHCH}$-bound CYP11A1 complex. Obviously, this could have arisen from the heme mode seen at $479 \mathrm{~cm}^{-1}$ in the photodissociated sample we have generated in the work presented here (Figure 5 , traces $C$ and $D$ ). 


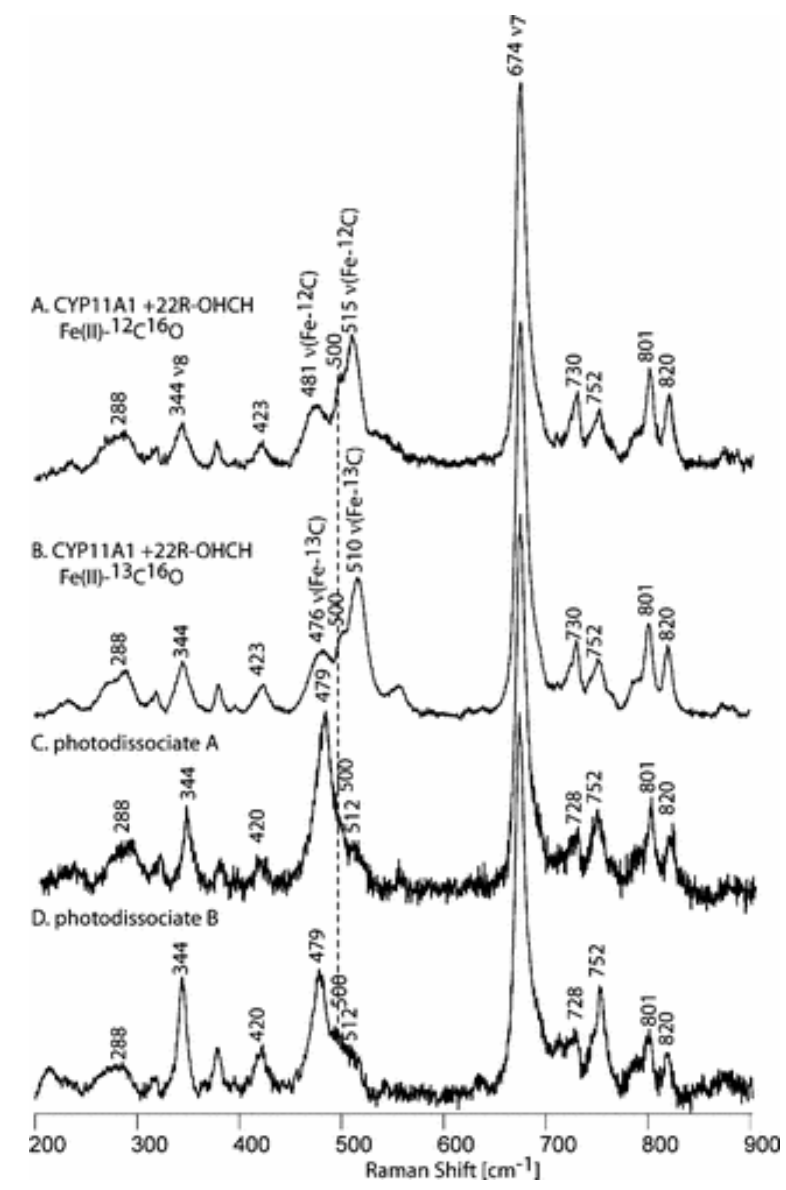

Figure 5. Isotope effect of $22 \mathrm{R}-\mathrm{OHCH}$ CO adducts in buffer comprising $100 \mathrm{mM}$ phosphate $(\mathrm{pH}$ 7.4), $0.1 \mathrm{mM}$ DTT, and $0.1 \mathrm{mM}$ EDTA. The excitation line was $442.4 \mathrm{~nm}$, and the acquisition time was 60 min at room temperature. Ferrous $\mathrm{CO}$ adducts with $(\mathrm{A})$ a ${ }^{12} \mathrm{CO}$ isotope and $(\mathrm{B}) \mathrm{a}{ }^{13} \mathrm{CO}$ isotope and their photodissociated forms ( $C$ and $D$, respectively). 


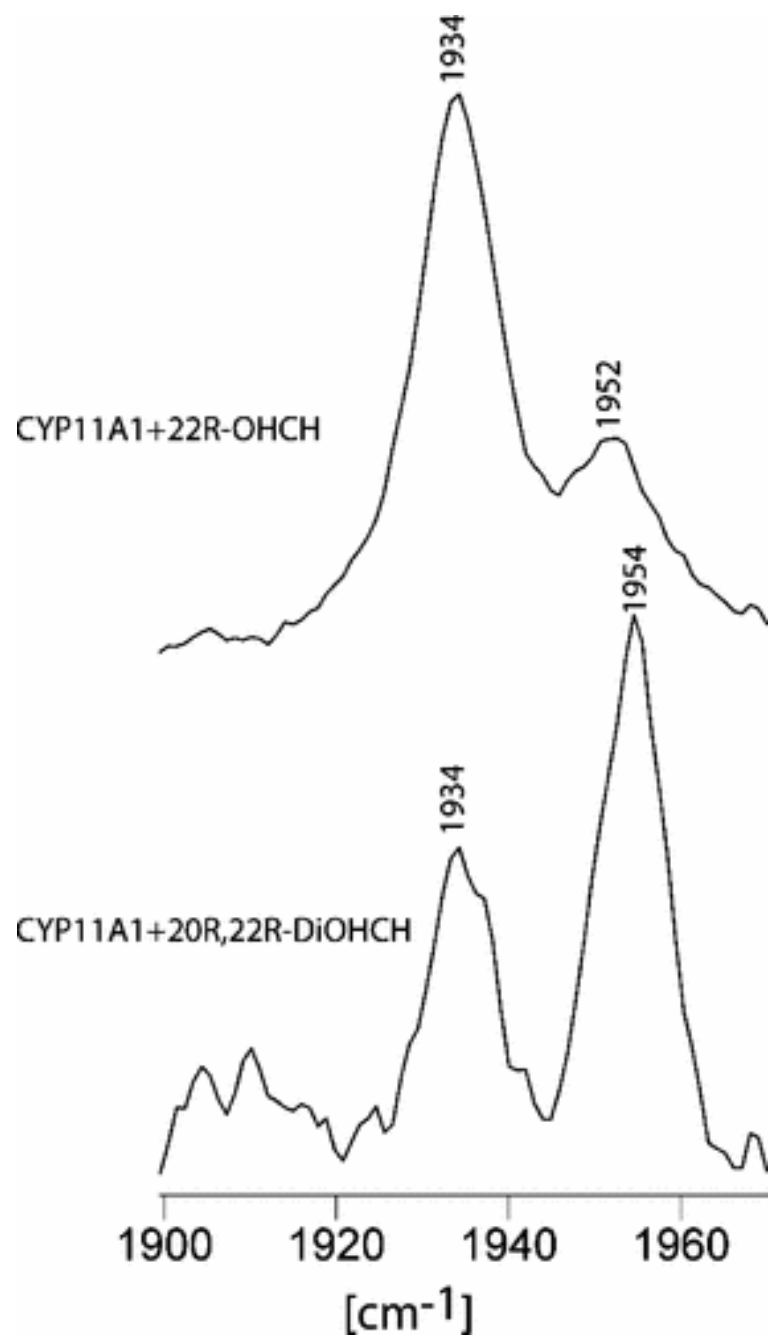

Figure 6. FTIR results for high-frequency CYP11A1 with substrate $22 R-O H C H$ and $20 R, 22 R$ DiOHCH ferrous CO forms in $100 \mathrm{mM}$ phosphate buffer (pH 7.4), $0.1 \mathrm{mM}$ DTT, and $0.1 \mathrm{mM}$ EDTA.

Given these clarified spectral traces for the $22 \mathrm{R}-\mathrm{OHCH}$-bound ferrous $\mathrm{CO}$ adduct, the most reasonable conclusion for this species is that this directed $\mathrm{C}-\mathrm{O}-\mathrm{H}$ group interacts with the $\mathrm{Fe}-\mathrm{C}-$ $\mathrm{O}$ fragment to produce two different $\mathrm{Fe}-\mathrm{C}-\mathrm{O}$ conformers. Furthermore, it is also quite reasonable to conclude that the appearance of two $v(\mathrm{Fe}-\mathrm{C})$ and two $\mathrm{v}(\mathrm{C}-\mathrm{O})$ modes for the $20 R, 22 R$-DiOHCH-bound substrate can also be attributed to interactions of one or both $\mathrm{C}-\mathrm{OH}$ groups with the Fe-C-O fragment; indeed, the two pairs of $v(\mathrm{Fe}-\mathrm{C}) / \mathrm{v}(\mathrm{C}-\mathrm{O})$ frequencies are quite similar for both complexes. From this collective data set for the three substrates, it seems likely that (for the second and third substrates) the presence of one $\mathrm{C}-\mathrm{OH}$ group positioned quite near the $\mathrm{Fe}-\mathrm{C}-\mathrm{O}$ fragment leads to two Fe-C-O conformers, one with a disposition similar to that of the "unperturbed" $\mathrm{Fe}-\mathrm{C}-\mathrm{O}$ conformer of the $\mathrm{CH}$-bound enzyme and the other reflecting a reasonably strong $\mathrm{H}$-bonding interaction with the $\mathrm{C}-\mathrm{OH}$ group present on the substrate. 


\section{Effects of Substrate Structure and Adx Binding on the Fe-O-O Fragment of Dioxygen-Ligated Intermediates of CYP11A1}

As discussed above, recent rR studies of the oxy intermediates of CYP17 and CYP19, $(43$, $44)$ along with analogous studies of NOS, $(59,67,69,70,83)$ have shown that this technique is effective in detecting subtle structural differences in $\mathrm{H}$-bond interactions with the $\mathrm{Fe}-\mathrm{O}-\mathrm{O}$ fragment. Specifically, donation of a $\mathrm{H}$-bond to the proximal oxygen $\left(\mathrm{O}_{\mathrm{p}}\right)$ of the $\mathrm{Fe}-\mathrm{O}_{\mathrm{p}}-$ $\mathrm{O}_{\mathrm{t}}$ fragment, detected for the dioxy adduct of the 17-OH PREG sample,(43) which has recently been shown by $r R$ spectroscopy to persist upon reduction to the peroxo intermediate,(53)stabilizing it for attack on susceptible substrates, exhibits a relatively low $v(\mathrm{Fe}-$ O) frequency $\left(528 \mathrm{~cm}^{-1}\right)$. On the other hand, $\mathrm{H}$-bonding to the terminal oxygen $\left(\mathrm{O}_{\mathrm{t}}\right)$ of the $\mathrm{Fe}-$ $\mathrm{O}_{\mathrm{p}}-\mathrm{O}_{\mathrm{t}}$ fragment of the 17-OH PROG-bound sample, which exhibits a relatively high $v(\mathrm{Fe}-\mathrm{O})$ frequency of $546 \mathrm{~cm}^{-1},(43)$ promotes formation of the hydroperoxo intermediate, ultimately leading to $\mathrm{O}-\mathrm{O}$ bond cleavage and Compound I formation, an intermediate that effectively mediates the more extensively studied hydroxylation reactions. Clearly, the rR technique is an important tool for documenting these structural variations that, nevertheless, carry profound functional consequences. $(14,15)$

Given this demonstrated utility of $r R$ spectroscopy for structural definition of these active site Fe-O-O fragments, efforts were made here, for the first time, to acquire rR spectra of these dioxygen adducts of CYP11A1 with all three natural substrates, seeking to detect any telltale differences in the $\mathrm{rR}$ spectra that might reveal important $\mathrm{H}$-bonding differences for the three substrates, as well as allowing detection of rearrangements of such bonding interactions upon association of CYP11A1 with Adx. To study these relatively unstable oxy intermediates encountered within the catalytic cycles for these three natural substrates of CYP11A1, special procedures were required, as summarized earlier in Materials and Methods. Inasmuch as no differential effects of the three substrates on the Fe-S linkage in the heme proximal pocket were seen in the studies of the $v(\mathrm{Fe}-\mathrm{S})$ modes (vide supra), all effects observed here are presumed to arise from distal side structural perturbations.

\section{Cholesterol-Bound OxyCYP11A1}

The $415.4 \mathrm{~nm}$ line from a krypton ion laser, which is in resonance with the Soret transition of the $\mathrm{CH}$-bound CYP11A1, was used to measure this complex. It is noted that, because of the relatively low signal-to-noise ratio that can be attained for these frozen oxy-CYP samples, definitive identification of the key internal modes of the Fe-O-O fragments is most readily accomplished via generation of the ${ }^{16} \mathrm{O}_{2} /{ }^{18} \mathrm{O}_{2}$ difference traces, which are shown in Figure 7. The $\mathrm{v}(\mathrm{O}-\mathrm{O})$ modes are seen in the high-frequency region, shown as traces $\mathrm{A}$ and $\mathrm{B}$ (large spectrum) for samples with and without $\mathrm{Adx}$, respectively. The $v(\mathrm{Fe}-\mathrm{O})$ modes, seen in the low-frequency region, are shown as traces $A$ and $B$ (small spectrum) for oxyCYP11A1 with and without $A d x$. 


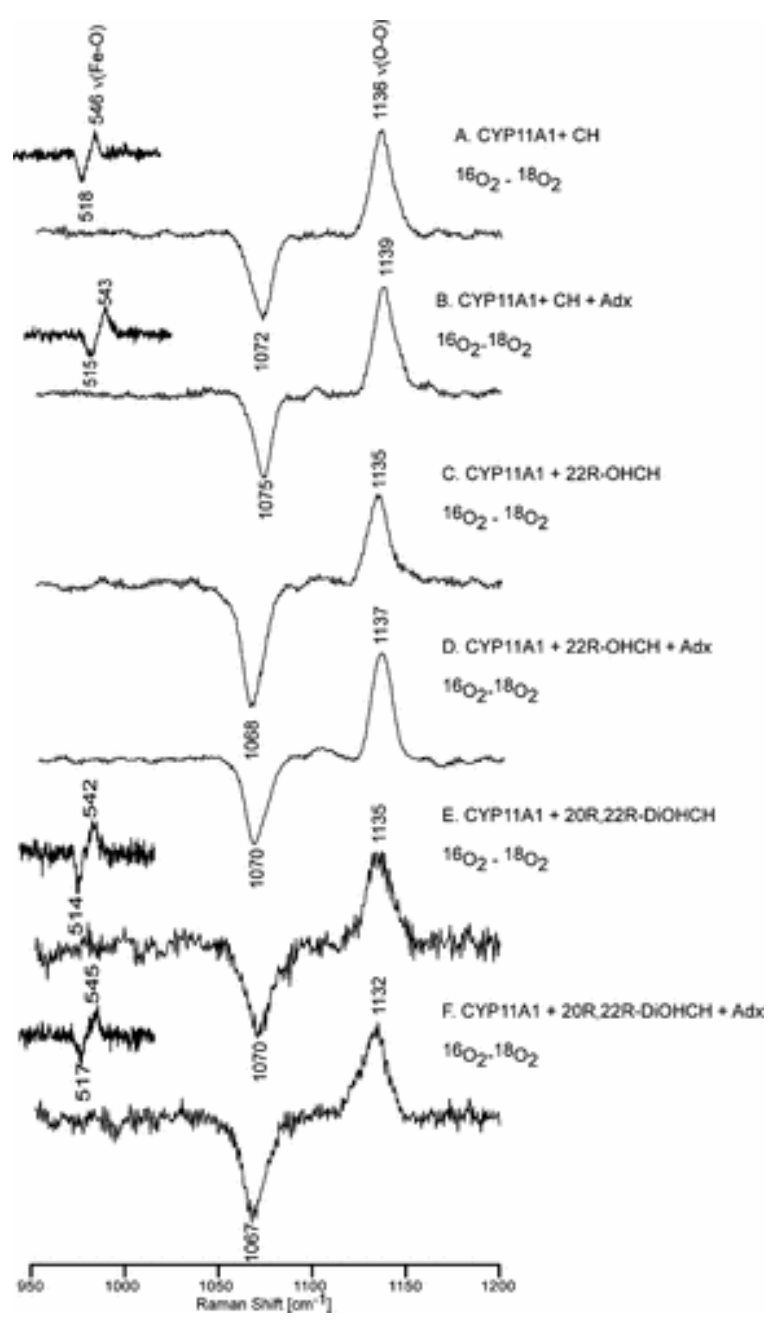

Figure 7. Oxy samples for all the substrates with and without Adx in $100 \mathrm{mM}$ phosphate buffer containing $0.1 \mathrm{mM}$ EDTA and $0.1 \mathrm{mM}$ DTT. The insets above show the $\mathrm{v}\left(\mathrm{Fe}-{ }^{16} \mathrm{O}\right)-\mathrm{v}\left(\mathrm{Fe}-{ }^{18} \mathrm{O}\right)$ difference features.

In the low-frequency spectra, the $v\left(\mathrm{Fe}-{ }^{16} \mathrm{O}\right)$ mode is assigned at $546 \mathrm{~cm}^{-1}$ and the $\mathrm{v}\left(\mathrm{Fe}-{ }^{18} \mathrm{O}\right)$ at $518 \mathrm{~cm}^{-1}$ for the cholesterol-bound form, a shift of $28 \mathrm{~cm}^{-1}$ (calculated shift of $25 \mathrm{~cm}^{-1}$ ). As was outlined above in the first paragraphs of this section, this set of values for $v(\mathrm{Fe}-\mathrm{O})$ and $v(\mathrm{O}-\mathrm{O})$ is quite similar to that obtained for camphor-bound oxyCYP101 and for oxyCYP17 and oxyCYP19 with those substrates that are known to be converted via Compound I processing. The conclusion emerging from this is that conversion of $\mathrm{CH}$ to $22-\mathrm{OHCH}$ is also likely to proceed through a Compound I intermediate. This finding has long been generally accepted, with recent electron paramagnetic resonance (EPR) studies providing results that strongly support the proposed involvement of Compound I in this first step.(60) Significantly, the sample prepared with Adx exhibits a $v\left(\mathrm{Fe}-{ }^{16} \mathrm{O}\right)$ mode at $543 \mathrm{~cm}^{-1}$ and a corresponding $v\left(\mathrm{Fe}-{ }^{18} \mathrm{O}\right)$ mode at $515 \mathrm{~cm}^{-}$ ${ }^{1}$; this $\sim 3 \mathrm{~cm}^{-1}$ downshift of $\mathrm{v}(\mathrm{Fe}-\mathrm{O})$ upon addition of $\mathrm{Adx}$ reflects a slight weakening of the $\mathrm{Fe}-$ $\mathrm{O}$ bond when $\mathrm{Adx}$ is present. On the other hand, the $\mathrm{v}\left({ }^{16} \mathrm{O}-{ }^{16} \mathrm{O}\right.$ ) (at $\left.1136 \mathrm{~cm}^{-1}\right)$ and $\mathrm{v}\left({ }^{18} \mathrm{O}-{ }^{18} \mathrm{O}\right.$ ) (at $1072 \mathrm{~cm}^{-1}$ ) modes shift up to 1139 and $1075 \mathrm{~cm}^{-1}$, respectively, upon addition of $A d x$, the combined results suggesting that the interaction with $\mathrm{Adx}$ might slightly weaken the $\mathrm{H}$-bonding interaction with the distal oxygen atom of the $\mathrm{O}-\mathrm{O}$ bond. 


\section{R-OHCH-Bound OxyCYP11A1}

Figure 7 shows the difference spectra for this species, both in the absence and presence of Adx. The high-frequency region (right panel, traces $C$ and $D$ ) shows the same pattern that was observed for the cholesterol-bound sample, exhibiting the $\left.\mathrm{v}^{(16} \mathrm{O}-{ }^{16} \mathrm{O}\right)$ mode at $1135 \mathrm{~cm}^{-1}$, with the $v\left({ }^{18} \mathrm{O}-{ }^{18} \mathrm{O}\right)$ mode being observed at $1068 \mathrm{~cm}^{-1}$. Also, like that of the $\mathrm{CH}$-bound sample, upon Adx binding, the $v\left({ }^{16} \mathrm{O}-{ }^{16} \mathrm{O}\right)$ mode shifts up to $1137 \mathrm{~cm}^{-1}$, with the corresponding $\mathrm{v}\left({ }^{18} \mathrm{O}-{ }^{18} \mathrm{O}\right)$ mode appearing at $1070 \mathrm{~cm}^{-1}$, an isotopic shift in reasonable agreement with that expected for a diatomic $\mathrm{O}-\mathrm{O}$ oscillator $\left(\sim 65 \mathrm{~cm}^{-1}\right)$. Unfortunately, though numerous attempts to observe the telltale $v(\mathrm{Fe}-\mathrm{O})$ mode were made, employing multiple excitation lines, including the $441.6 \mathrm{~nm}$ line from a He:Cd laser, no evidence was obtained for its enhancement. These efforts are summarized in the Supporting Information, along with a discussion of structural and electronic factors that can affect the degree of resonance enhancement of the modes that are essentially isolated to the $\mathrm{Fe}-\mathrm{O}-\mathrm{O}$ fragment. In the absence of observable $\mathrm{v}(\mathrm{Fe}-\mathrm{O})$ modes, it is not possible to draw conclusions about the status of the $\mathrm{Fe}-\mathrm{O}-\mathrm{O}$ fragment with respect to its disposition toward the $\mathrm{O}-\mathrm{O}$ bond cleavage process involved in the hydroxylation pathways. Nevertheless, the well-documented generation of the $20 R, 22 R$-DiOHCH product is consistent with the proposal that a Compound I intermediate is involved. Indeed, recent experimental work reported by Hoffman and co-workers, employing cryoradiolysis studies with EPR detection, has provided convincing arguments for this assertion. $(60,61)$

\section{R,22R-DiOHCH-Bound OxyCYP11A1}

Figure 7 also shows the difference spectra obtained for the oxy complexes of the $20 R, 22 R$ DiOHCH-bound CYP11A1 complex with and without Adx. The difference patterns for the spectral region containing the $\mathrm{v}(\mathrm{O}-\mathrm{O})$ modes were measured with Soret excitation $(415.4 \mathrm{~nm})$, as was done for the previous substrates. However, no clear difference pattern for $\mathrm{v}(\mathrm{Fe}-\mathrm{O})$ could be observed in the low-frequency region. The same efforts were employed that were used to try to enhance the $v(\mathrm{Fe}-\mathrm{O})$ modes of the $22 \mathrm{R}-\mathrm{OHCH}$ sample (vide supra). In this case, the $v(\mathrm{Fe}-\mathrm{O})$ mode was effectively enhanced using the $441.6 \mathrm{~nm}$ excitation line from the $\mathrm{He}: \mathrm{Cd}$ laser. The data acquired for the enzyme bound with the third substrate, $20 R, 22 R$ - DiOHCH, reveal the $v(\mathrm{Fe}-$ ${ }^{16} \mathrm{O}$ ) stretching mode at $542 \mathrm{~cm}^{-1}$ and the $\left.\mathrm{v}^{16} \mathrm{O}-{ }^{16} \mathrm{O}\right)$ mode at $1135 \mathrm{~cm}^{-1}$. Interestingly, the effect of Adx binding on this species is the opposite of its effect on the enzyme bound with the first two substrates; i.e., binding of Adx to the samples containing the first two substrates increases the strength of the $\mathrm{O}-\mathrm{O}$ bond, simultaneously decreasing the strength of the Fe-O bond [in the case of the $\mathrm{CH}$-bound form, wherein Raman scattering by the $\mathrm{v}(\mathrm{Fe}-\mathrm{O})$ mode is enhanced], while Adx binding on the sample containing $20 R, 22 R$ - $\mathrm{DiOHCH}$ increases the strength of the $\mathrm{Fe}-\mathrm{O}$ bond and decreases the strength of the $\mathrm{O}-\mathrm{O}$ bond.

A key finding in the studies of these oxy complexes with the three natural substrates is that the CYP11A1- $\mathrm{CH}$ oxy complex yields frequencies for the $\mathrm{v}(\mathrm{Fe}-\mathrm{O})$ and $\mathrm{v}(\mathrm{O}-\mathrm{O})$ modes that are very similar to those obtained for the oxy complex of CYP11A1 bound to $20 R, 22 R$-DiOHCH; i.e., both are quite similar to those seen for the oxy complex of P450cam complexes and those observed for OxyCYP17A1 bearing the 17-OH PROG substrate, all of which encounter hydrogen bonding interactions involving the terminal oxygen of the $\mathrm{Fe}-\mathrm{O}-\mathrm{O}$ fragment, interactions that promote $\mathrm{O}-\mathrm{O}$ bond cleavage and Compound I formation. $(18,44,71)$ This leads to the conclusion that the bond cleavage step likely proceeds through the Compound I intermediate, in agreement with 
previous work. $(60,61)$ With the addition of $\mathrm{Adx}$, the $\mathrm{v}(\mathrm{Fe}-\mathrm{O})$ frequency increases, indicating the strengthening the $\mathrm{Fe}-\mathrm{O}$ bond; the observed decrease in the $\mathrm{v}(\mathrm{O}-\mathrm{O})$ frequency indicates the corresponding weakening the $\mathrm{O}-\mathrm{O}$ bond. Both of these shifts are consistent with donation of a slightly stronger hydrogen bond to the terminal oxygen, a change that would lower peroxoreactivity and further promote $\mathrm{O}-\mathrm{O}$ bond cleavage of the $\mathrm{Fe}-\mathrm{O}-\mathrm{O}$ fragment and formation of Compound I.

\section{Relationship of Findings from rR Spectroscopy to Recent EPR and Electron Nuclear Double Resonance (ENDOR) Work}

Finally, it is of interest to point out that results reported for EPR and ENDOR studies of CYP11A1, with all three physiologically important substrates, $(60,61)$ provide indirect evidence from analysis of cryoreduced samples that the enzyme substrate complexes formed with each of these three substrates gave rise to oxy complexes existing in three different conformations, with $\mathrm{H}$-bonded forms generating hydroperoxo species following cryoradiolysis at $77 \mathrm{~K}$, while non- $\mathrm{H}-$ bonded oxy precursors yielded either a ferric-peroxo species or, in the special case of $22 \mathrm{OH}-\mathrm{CH}$, a ferrous-superoxo species. $(60,61,84)$ In support of this argument, detailed analysis of the $r R$ spectra of these oxygenated precursors shown in Figure S1 is consistent with the presence of three conformers in each of the substrate-bound forms, as had been deduced from analysis of the observed EPR and ENDOR spectra of the cryoreduced samples. $(60,61)$ The only somewhat surprising result from the earlier EPR work is that, while a non-H-bonded form in the oxy complex when $\mathrm{CH}$ is bound gives rise to a peroxo species at $77 \mathrm{~K}$, the non- $\mathrm{H}$-bonded species in the oxy complex with the 22-OH-CH substrate was correlated with a ferrous-superoxo species in the cryoreduced sample; $(60,61)$ i.e., the two samples display similar rR spectra of the oxy precursors but give rise to two different formulations of isoelectronic species in the cryoreduced forms. One possible explanation arises upon consideration of subtle but potentially effective $\mathrm{H}$ bonding differences that might exist in these two cases. Thus, while the $\mathrm{C}_{22}-\mathrm{OH}$ fragment of bound 22- $\mathrm{OH}-\mathrm{CH}$ is known to coordinate to the heme iron, neither the $\mathrm{C}_{20}-\mathrm{OH}$ groups nor the $\mathrm{C}_{22}-\mathrm{OH}$ groups coordinate to the heme iron when $20,22-\mathrm{DiOH}-\mathrm{CH}$ is bound; i.e., there are apparently critical active site $\mathrm{H}$-bonding interactions that position the 22-OH fragment of only the $22-\mathrm{OH}-\mathrm{CH}$ substrate in an orientation that directs the unpaired electrons to interact with the heme iron. Such interaction might persist in both the dioxy and cryoreduced sample, such that the lone pair interacts directly with the bound Fe-O-O superoxo fragment, favoring the generation of the ferrous-superoxo rather than the ferric-peroxo formulation.

\section{Summary}

These newly acquired $\mathrm{rR}$ data for the ferric and ferrous CO forms of CYP11A1 are partially consistent with what was published previously but also clarify certain ambiguities arising from the apparent photodissociation of $\mathrm{CO}$ during the measurement in the case of the complex between $22 \mathrm{R}-\mathrm{OHCH}$ and $\mathrm{CYP} 11 \mathrm{~A} 1$ in the ferrous-CO form.(50-52) The data presented in this work clearly show that the enzyme bound with the non-H-bonding substrate, $\mathrm{CH}$, yields only one set of vibrational modes for the $\mathrm{CO}$ adduct, i.e., $\mathrm{v}(\mathrm{Fe}-\mathrm{C})$ at $482 \mathrm{~cm}^{-1}$ and $\mathrm{v}(\mathrm{C}-\mathrm{O})$ at $1952 \mathrm{~cm}^{-1}$. On the other hand, for the two substrates possessing hydroxyl substituents that are well positioned to $\mathrm{H}$-bond with the bound $\mathrm{Fe}-\mathrm{C}-\mathrm{O}$ fragment, two sets of $\mathrm{Fe}-\mathrm{C}-\mathrm{O}$ vibrational modes are seen. Thus, for both enzyme-substrate complexes, $v(\mathrm{Fe}-\mathrm{C})$ and $\mathrm{v}(\mathrm{C}-\mathrm{O})$ are seen at 482 and $1954 \mathrm{~cm}^{-1}$, 
respectively, which are quite similar to those observed for the non- $\mathrm{H}$-bonding $\mathrm{CH}$ substrate. On the other hand, the presence of one or two $\mathrm{H}$-bonding hydroxyl groups near the $\mathrm{Fe}-\mathrm{C}-\mathrm{O}$ fragment generates a new set of modes having the $\mathrm{v}(\mathrm{Fe}-\mathrm{C})$ mode at $515 \mathrm{~cm}^{-1}\left(\right.$ or $510 \mathrm{~cm}^{-1}$ ) and the $v(C-O)$ mode at $1934 \mathrm{~cm}^{-1}$, both sets of data being entirely consistent with $\mathrm{H}$-bonding to the $\mathrm{Fe}-\mathrm{C}-\mathrm{O}$ fragment. The data acquired for the protein-protein complex between CYP11A1 and $A d x$ also show the effect of $\mathrm{Adx}$ on the active sites of the ferric- and ferrous-CO forms to be minimal.

Finally, this first study of the rR spectra of the dioxygen adducts of CYP11A1 with all three substrates revealed vibrational spectral patterns that are quite similar. On the basis of conclusions drawn from work on dioxygen adducts of several other cytochromes P450, including CYP101, CYP17, and CYP19, the $v(\mathrm{Fe}-\mathrm{O})$ and $v(\mathrm{O}-\mathrm{O})$ frequencies observed here are those expected for the Fe-O-O fragment that is eventually converted to the Compound I intermediates upon reduction. Though it can be argued that the effective $\mathrm{H}$-donor for the various cases might be different [i.e., water for $\mathrm{CH}$ and substrate hydroxyl group(s) for the other two substrates], the $\mathrm{Fe}-\mathrm{O}-\mathrm{O}$ fragment in each case is apparently poised to generate the classic Compound I active oxidant. Finally, it is noted that, unlike the $\mathrm{CO}$ adducts, binding of adrenodoxin does have a significant impact on the status of the dioxygen complexes, presumably because of an $\mathrm{Adx}$-induced change in $\mathrm{H}$-bonding to the $\mathrm{Fe}-\mathrm{O}-\mathrm{O}$ fragment, which is known to be more sensitive to this interaction than are Fe-C $-\mathrm{O}$ fragments.(42)

\section{References}

1 Sigel, A., Sigel, H., and Sigel, R. K. O. (2007) The Ubiquitous Roles of Cytochrome P450 Proteins. In Metal lons in Life Sciences, John Wiley \& Sons, Ltd., Hoboken, NJ.

$\underline{2}$ Ortiz de Montelano, P. R. (2015) Cytochrome P450: Structure, Mechanism, and Biochemistry,Kluwer Academic/Plenum, New York.

$\underline{3}$ Miller, W. L. and Auchus, R. J. (2011) The molecular biology, biochemistry, and physiology of human steroidogenesis and its disorders Endocr. Rev. 32, 81- 151DOI: 10.1210/er.20100013

4 Stone, D. and Hechter, O. (1954) Studies on ACTH action in perfused bovine adrenals: The site of action of ACTH in corticosteroidogenesis Arch. Biochem. Biophys. 51, 457-469DOI: 10.1016/0003-9861(54)90501-9

$\underline{5}$ Simpson, E. R. and Boyd, G. S. (1966) The cholesterol side-chain cleavage system of the adrenal cortex: A mixed-function oxidase Biochem. Biophys. Res. Commun. 24, 10- 17DOI: 10.1016/0006-291X(66)90402-5

$\underline{6}$ Burstein, S. and Gut, M. (1976) Intermediates in the conversion of cholesterol to pregnenolone: Kinetics and mechanism Steroids 28, 115-131DOI: 10.1016/0039128X(76)90131-8

$\underline{7}$ Hume, R., Kelly, R. W., Taylor, P. L., and Boyd, G. S. (1984) The catalytic cycle of cytochrome P450 scc and intermediates in the conversion of cholesterol to pregnenolone Eur. J. Biochem. 140,583- 591DOI: 10.1111/j.1432-1033.1984.tb08142.x

$\underline{8}$ Lambeth, J. D., Seybert, D. W., Lancaster, J. R., Jr., Salerno, J. C., and Kamin, H. (1982)Steroidogenic electron transport in adrenal cortex mitochondria Mol. Cell. Biochem. 45, 13-31DOI: 10.1007/BF01283159 
9 Ewen, K. M., Kleser, M., and Bernhardt, R. (2011) Adrenodoxin: the archetype of vertebratetype [2Fe-2S] cluster ferredoxins Biochim. Biophys. Acta, Proteins

Proteomics 1814, 111- 125DOI: 10.1016/j.bbapap.2010.06.003

10 Bangcharoenpaurpong, O., Rizos, A. K., Champion, P. M., Jollie, D., and Sligar, S. G. (1986)Resonance Raman detection of bound dioxygen in cytochrome P-450cam J. Biol. Chem. 261,8089- 8092

11 Hu, S., Schneider, A. J., and Kincaid, J. R. (1991) Resonance raman studies of oxycytochrome P450cam: effect of substrate structure on v(O-O) and v(Fe-O) J. Am. Chem. Soc.113, 4815-4822DOI: 10.1021/ja00013a016

12 Tuckey, R. C. and Kamin, H. (1982) The Oxyferro Complex of Adrenal Cytochrome P-450ccc. Effect of cholesterol and intermediates on its stability and optical characteristics J. Biol. Chem.257, 9309- 9314

13 Tuckey, R. C. and Kamin, H. (1983) Kinetics of $\mathrm{O}_{2}$ and CO Binding to Adrenal Cytochrome P450scc: Effect of Cholesterol, Intermediates and Phosphatidylcholine Vesicles J. Biol. Chem.258, 4232- 4237

14 Akhtar, M. and Wright, J. N. (2015) Acyl-Carbon Bond Cleaving Cytochrome P450 Enzymes: CYP17A1, CYP19A1 and CYP51A1 Adv. Exp. Med. Biol. 851, 107- 130DOI: 10.1007/9783-319-16009-2_4

15 Akhtar, M., Wright, J. N., and Lee-Robichaud, P. (2011) A Review of Mechanistic Studies on Aromatase (CYP19) and 17 $\alpha$ - Hydroxylase-17,20-Lyase (CYP17) J. Steroid Biochem. Mol. Biol.125, 2- 12DOI: 10.1016/j.jsbmb.2010.11.003

16 Denisov, I. G., Makris, T. M., Sligar, S. G., and Schlichting, I. (2005) Structure and chemistry of cytochrome P 450 Chem. Rev. (Washington, DC, U. S.) 105, 2253-2277DOI: 10.1021/cr0307143

17 Rittle, J. and Green, M. T. (2010) Cytochrome P450 compound I: capture, characterization, and C-H bond activation kinetics Science 330, 933-937DOI: 10.1126/science.1193478

18 Groves, J. T. (2006) High-valent iron in chemical and biological oxidations J. Inorg. Biochem.100, 434-447DOI: 10.1016/j.jinorgbio.2006.01.012

19 Meunier, B., de Visser, S. P., and Shaik, S. (2004) Mechanism of oxidation reactions catalyzed by cytochrome P450 enzymes Chem. Rev. 104, 3947- 3980DOI: 10.1021/cr020443g

$\underline{20}$ Krest, C. M., Onderko, E. L., Yosca, T. H., Calixto, J. C., Karp, R. F., Livada, J., Rittle, J., andGreen, M. T. (2013) Reactive Intermediates in Cytochrome P450 Catalysis J. Biol. Chem. 288,17074-17081DOI: 10.1074/jbc.R113.473108

21 McQuarters, A. B., Wolf, M. W., Hunt, A. P., and Lehnert, N. (2014) 1958-2014: After 56 years of research, cytochrome $P 450$ reactivity is finally explained Angew. Chem., Int.

Ed. 53, 4750-4752DOI: 10.1002/anie.201402404

22 Groves, J. T. (2014) Enzymatic C-H bond activation: Using push to get pull Nat. Chem. 6,89- 91DOI: 10.1038/nchem.1855

$\underline{23}$ Lambeth, J. D., Seybert, D. W., Kamin, H., Chem, J. B., David, J., and Seybert, W. (1979) Ionic effects on adrenal steroidogenic electron transport. The role of adrenodoxin as an electron shuttle J. Biol. Chem. 254, 7255- 7264

24 Kido, T. and Kimura, T. (1979) The formation of binary and ternary complexes of cytochrome $\mathrm{P}-450 \mathrm{scc}$ with adrenodoxin and adrenodoxin reductase.adrenodoxin complex J. Biol. Chem. 254, 11806- 11815 
25 Turko, I. V., Adamovich, T. B., Kirillova, N. M., Usanov, S., and Chashchin, V. (1989) Crosslinking studies of the cholesterol hydroxylation system from bovine adrenocortical mitochondriaBiochim. Biophys. Acta, Protein Struct. Mol. Enzymol. 996, 37-42DOI: 10.1016/0167-4838(89)90091-5

26 Lambeth, J. D. and Pemberg, O. S. (1983) Cytochrome P-450scc-Adrenodoxin Complex J. Biol. Chem. 258, 5596- 5602

27 Lambeth, J. D. and Kriengsiri, S. (1985) Cytochrome P-450scc-Adrenodoxin Interactions J. Biol. Chem. 260, 8810- 8816

$\underline{28}$ Strushkevich, N., MacKenzie, F., Cherkesova, T., Grabovec, I., Usanov, S., and Park, H.W.(2011) Structural basis for pregnenolone biosynthesis by the mitochondrial monooxygenase system Proc. Natl. Acad. Sci. U. S. A. 108, 10139-10143DOI: 10.1073/pnas.1019441108

$\underline{29}$ Kincaid, J. R. (2000) Resonance Raman spectra of heme proteins and model compounds. In The Porphyrin Handbook (Kadish, K. M., Smith, K., and Guilard, R., Eds.) pp 225-291,Academic Press, New York.

30 Mak, P. J. (2016) Resonance Raman spectroscopy as a structural probe of cytochrome P450 enzymatic cycle. In Handbook of Porphyrin Science (Kadish, K. M., Smith, K., and Guilard, R., Eds.) pp 1-120, World Scientific Publishing Co., Singapore.

31 Mak, P. J., Zhu, Q., and Kincaid, J. R. (2013) Using resonance Raman cross-section data to estimate the spin state populations of Cytochromes P450 J. Raman Spectrosc. 44, 1792-1794DOI: 10.1002/jrs.4401

32 Chen, Z., Ost, T. W. B., and Schelvis, J. P. M. (2004) Phe393 Mutants of Cytochrome P450 BM3 with Modified Heme Redox Potentials Have Altered Heme Vinyl and Propionate Conformations Biochemistry 43, 1798-1808DOI: 10.1021/bi034920g

33 Mak, P. J., Kaluka, D., Manyumwa, M. E., Zhang, H., Deng, T., and Kincaid, J. R. (2008)Defining resonance Raman spectral responses to substrate binding by cytochrome P450 from Pseudomonas putida Biopolymers 89, 1045- 1053DOI: 10.1002/bip.21058

34 Smulevich, G., Feis, A., Howes, B. D., and Ivancich, A. (2010) Structure-function relationships among heme peroxidases: New insights from electronic absorption, resonance Raman and multifrequency electron paramagnetic resonance spectroscopies Handb. Porphyrin Sci. 10,367-453DOI: 10.1142/9789814307246_0003

35 Friedman, J. M. (1994) Time-resolved resonance Raman spectroscopy as probe of structure, dynamics, and reactivity in hemoglobin Methods Enzymol. 232, 205-231DOI: 10.1016/0076-6879(94)32049-7

36 Kitagawa, T. and Mizutani, Y. (1994) Resonance Raman spectra of highly oxidized metalloporphyrins and heme proteins Coord. Chem. Rev. 135-136, 685- 735DOI: 10.1016/0010-8545(94)80081-2

37 Terner, J., Palaniappan, V., Gold, A., Weiss, R., Fitzgerald, M. M., Sullivan, A. M., and Hosten, C. M. (2006) Resonance Raman spectroscopy of oxoiron(IV) porphyrin pi-cation radical and oxoiron(IV) hemes in peroxidase intermediates J. Inorg. Biochem. 100, 480- 501DOI: 10.1016/j.jinorgbio.2006.01.008

38 Marzocchi, M. P. and Smulevich, G. (2003) Relationship between heme vinyl conformation and the protein matrix in peroxidases J. Raman Spectrosc. 34, 725-736DOI: 10.1002/jrs.1037 
$39 \mathrm{Hu}$, S., Smith, K. M., and Spiro, T. G. (1996) Assignment of Protoheme Resonance Raman Spectrum by Heme Labeling in Myoglobin J. Am. Chem. Soc. 118, 12638-12646DOI: 10.1021/ja962239e

40 Rwere, F., Mak, P. J., and Kincaid, J. R. (2008) The impact of altered protein-heme interactions on the resonance raman spectra of heme proteins. Studies of heme rotational disorder Biopolymers 89, 179-186DOI: 10.1002/bip.20887

41 Cerda-Colon, J. F., Silfa, E., and Lopez-Garriga, J. (1998) Unusual rocking freedom of the heme in the hydrogen sulfide-binding hemoglobin from Lucina pectinata J. Am. Chem. Soc. 120,9312- 9317DOI: 10.1021/ja972654m

42 Spiro, T. G., Soldatova, A. V, and Balakrishnan, G. (2013) CO, NO and $\mathrm{O}_{2}$ as Vibrational Probes of Heme Protein Interactions Coord. Chem. Rev. 257, 511- 527DOI: 10.1016/j.ccr.2012.05.008

43 Gregory, M., Mak, P. J., Sligar, S. G., and Kincaid, J. R. (2013) Differential hydrogen bonding in human CYP17 dictates hydroxylation versus lyase chemistry Angew. Chem., Int. Ed. 52, 5342-5345DOI: 10.1002/anie.201300760

44 Mak, P. J., Luthra, A., Sligar, S. G., and Kincaid, J. R. (2014) Resonance Raman spectroscopy of the oxygenated intermediates of human CYP19A1 implicates a Compound I intermediate in the final lyase step J. Am. Chem. Soc. 136, 4825-4828DOI: 10.1021/ja500054c

45 Champion, P. M., Stallard, B. R., Wagner, G. C., and Gunsalus, I. C. (1982) Resonance Raman detection of an Fe-S bond in cytochrome P450cam J. Am. Chem.

Soc. 104, 5469- 5473DOI: 10.1021/ja00384a037

46 Unno, M., Christian, J. F., Benson, D. E., Gerber, N. C., Sligar, S. G., and Champion, P. M. (1997)Resonance Raman investigations of cytochrome P450cam complexed with putidaredoxin J. Am. Chem. Soc. 119, 6614-6620DOI: 10.1021/ja963785a

47 Mak, P. J., Yang, Y., Im, S., Waskell, L. A., and Kincaid, J. R. (2012) Experimental Documentation of the Structural Consequences of Hydrogen-Bonding Interactions to the Proximal Cysteine of a Cytochrome P450 Angew. Chem., Int. Ed. 51, 10403- 10407DOI: 10.1002/anie.201205912

48 Mak, P. J., Im, S.-C., Zhang, H., Waskell, L. A., and Kincaid, J. R. (2008) Resonance Raman studies of cytochrome P450 2B4 in its interactions with substrates and redox partnersBiochemistry 47, 3950-3963DOI: 10.1021/bi800034b

$\underline{49}$ Sjodin, T., Christian, J. F., Macdonald, I. D. G., Davydov, R., Unno, M., Sligar, S. G., Hoffman, B. M., and Champion, P. M. (2001) Resonance Raman and EPR Investigations of the D251N Oxycytochrome P450 cam/Putidaredoxin Complex Biochemistry 40, 6852-6859DOI: 10.1021/bi002510b

50 Tsubaki, M., Hiwatashi, A., and Ichikawa, Y. (1986) Effects of cholesterol and adrenodoxin binding on the heme moiety of cytochrome P-450scc: a resonance Raman study Biochemistry25, 3563-3569DOI: 10.1021/bi00360a014

$\underline{51}$ Tsubaki, M., Hiwatashi, A., and Ichikawa, Y. (1987) Effects of cholesterol analogues and inhibitors on the heme moiety of cytochrome P-450scc: a resonance Raman study Biochemistry26, 4535-4540DOI: 10.1021/bi00388a055

52 Tsubaki, M., Yoshikawa, J. S., Ichikawa, Y., and Yu, N. T. (1992) Effects of Cholesterol SideChain Groups and Adrenodoxin Binding on the Vibrational Modes of Carbon Monoxide 
Bound to Cytochrome P-450scc: Implications of the Productive and Nonproductive Substrate BindingsBiochemistry 31, 8991-8999DOI: 10.1021/bi00152a041

53 Mak, P. J., Gregory, M. C., Denisov, I. G., Sligar, S. G., and Kincaid, J. R. (2015) Unveiling the crucial intermediates in androgen production Proc. Natl. Acad. Sci. U. S.

A. 112, 15856-15861DOI: 10.1073/pnas.1519376113

54 Spiro, T. G. and Soldatova, A. V. (2012) Ambidentate H-bonding of $\mathrm{NO}$ and $\mathrm{O}_{2}$ in heme proteins J. Inorg. Biochem. 115, 204-210DOI: 10.1016/j.jinorgbio.2012.05.013

55 Sen, K. and Hackett, J. C. (2010) Peroxo-Iron Mediated Deformylation in Sterol $14 \alpha-$ Demethylase Catalysis J. Am. Chem. Soc. 132, 10293-10305DOI: 10.1021/ja906192b

$\underline{56}$ Cho, K.-B. and Gauld, J. W. (2005) Second half-reaction of nitric oxide synthase: computational insights into the initial step and key proposed intermediate J. Phys. Chem. B 109,23706-23714DOI: 10.1021/jp054864o

57 Pant, K. and Crane, B. R. (2006) Nitrosyl - Heme Structures of Bacillus subtilis Nitric Oxide Synthase Have Implications for Understanding Substrate Oxidation Biochemistry 45, 2537-2544DOI: 10.1021/bi0518848

$\underline{58}$ Lu, C., Egawa, T., Wainwright, L. M., Poole, R. K., and Yeh, S.-R. (2007) Structural and functional properties of a truncated hemoglobin from a food-borne pathogen Campylobacter jejuni J. Biol. Chem. 282, 13627-13636DOI: 10.1074/jbc.M609397200

59 Chartier, F. J. M. and Couture, M. (2007) Substrate-specific interactions with the heme-bound oxygen molecule of nitric-oxide synthase J. Biol. Chem. 282, 20877-20886DOI: 10.1074/jbc.M701800200

60 Davydov, R., Gilep, A. A., Strushkevich, N. V, Usanov, S. A., and Hoffman, B. M. (2012)Compound I Is the Reactive Intermediate in the First Monooxygenation Step during Conversion of Cholesterol to Pregnenolone by Cytochrome P450scc: EPR/ENDOR/Cryoreduction/ Annealing Studies J. Am. Chem. Soc. 134, 17149- 17156DOI: 10.1021/ja3067226

61 Davydov, R., Strushkevich, N., Smil, D., Yantsevich, A., Gilep, A., Usanov, S., and Hoffman, B. M. (2015) Evidence That Compound I Is the Active Species in Both the Hydroxylase and Lyase Steps by Which P450scc Converts Cholesterol to Pregnenolone:

EPR/ENDOR/Cryoreduction/Annealing Studies Biochemistry 54, 7089- 7097DOI: 10.1021/acs.biochem.5b00903

$\underline{62}$ Yoshimoto, F. K., Jung, I. J., Goyal, S., Gonzalez, E., and Guengerich, F. P. (2016) IsotopeLabeling Studies Support the Electrophilic Compound I Iron Active Species, $\mathrm{FeO}^{3+}$, for the Carbon-Carbon Bond Cleavage Reaction of the Cholesterol Side-Chain Cleavage Enzyme, Cytochrome P450 11A1 J. Am. Chem. Soc. 138, 12124-12141DOI: 10.1021/jacs.6b04437

63 Tuckey, R. C. and Stevenson, P. M. (1984) Properties of Bovine Luteal Cytochrome P450scc Incorporated into Artificial Phospholipid Vesicles Int. J. Biochem. 16, 497-503DOI: 10.1016/0020-711X(84)90166-6

64 Tuckey, R. C. and Stevenson, P. M. (1984) Properties of Ferredoxin Reductase and Ferredoxin from the Bovine Corpus Luteum Int. J. Biochem. 16, 489-495DOI: 10.1016/0020711X(84)90165-4

65 Lambeth, J. D., Kitchen, E., Farooqui, A. A., Tuckey, R., and Kamin, H. (1982) Cytochrome P450scc-Substrate Interactions J. Biol. Chem. 257, 1876- 1884 
66 Shriver, D. F. and Dunn, J. B. R. (1974) Backscattering geometry for Raman spectroscopy of colored materials Appl. Spectrosc. 28, 319-323DOI: 10.1366/000370274774332371

67 Li, D., Kabir, M., Stuehr, D. J., Rousseau, D. L., and Yeh, S. (2007) Substrate- and IsoformSpecific Dioxygen Complexes of Nitric Oxide Synthase J. Am. Chem. Soc. 129, 6943-6951DOI: 10.1021/ja070683j

68 Khatri, Y., Gregory, M. C., Grinkova, Y. V., Denisov, I. G., and Sligar, S. G. (2014) Active site proton delivery and the lyase activity of human CYP17A1 Biochem. Biophys. Res. Commun. 443,179-184DOI: 10.1016/j.bbrc.2013.11.094

69 Couture, M., Stuehr, D. J., and Rousseau, D. L. (2000) The Ferrous Dioxygen Complex of the Oxygenase Domain of Neuronal Nitric-oxide Synthase J. Biol. Chem. 275, 3201- 3205DOI: 10.1074/jbc.275.5.3201

$\underline{70}$ Rousseau, D. L., Li, D., Couture, M., and Yeh, S.-R. (2005) Ligand-protein interactions in nitric oxide synthase J. Inorg. Biochem. 99, 306- 323DOI: 10.1016/j.jinorgbio.2004.11.007

$\underline{71}$ Khatri, Y., Luthra, A., Duggal, R., and Sligar, S. G. (2014) Kinetic solvent isotope effect in steady-state turnover by CYP19A1 suggests involvement of Compound 1 for both hydroxylation and aromatization steps FEBS Lett. 588, 3117- 3122DOI: 10.1016/j.febslet.2014.06.050

72 Abe, M., Kitagawa, T., and Kyogoku, Y. (1978) Resonance Raman spectra of octaethylporphyrinatonickel(II) and meso-deuterated and nitrogen-15 substituted derivatives. II. A normal coordinate analysis J. Chem. Phys. 69, 4526-4534DOI: 10.1063/1.436450

$\underline{73}$ Mast, N., Annalora, A. J., Lodowski, D. T., Palczewski, K., Stout, C. D., and Pikuleva, I. a. (2011)Structural basis for three-step sequential catalysis by the cholesterol side chain cleavage enzyme CYP11A1 J. Biol. Chem. 286, 5607-5613DOI: 10.1074/jbc.M110.188433

$\underline{74}$ Antonini, E. and Brunori, M. (1971) Hemoglobin and Myoglobin in Their Reactions with Ligands, North Holland Publishing Co., Amsterdam.

75 Pruitt, K. and Tenovuo, J. (1985) The Lactoperoxidase System: Chemistry and Biological Significance, Marcel Dekker, New York.

$\underline{76}$ Reiter, B. and Perraudin, J. P. (1991) in Peroxidases in Chemistry and Biology (Everse, J., Everse, K. E., and Grisham, M. B., Eds.) pp 143-180, CRC Press, Boca Raton, FL.

77 Sivaramakrishnan, S., Ouellet, H., Matsumura, H., Guan, S., Moënne-Loccoz, P., Burlingame, A. L., and Ortiz de Montellano, P. R. (2012) Proximal Ligand Electron Donation and Reactivity of the Cytochrome P450 Ferric-Peroxo Anion J. Am. Chem.

Soc. 134, 6673-6684DOI: 10.1021/ja211499q

$\underline{78}$ Mak, P. J., Gregory, M. C., Sligar, S. G., and Kincaid, J. R. (2014) Resonance Raman spectroscopy reveals that substrate structure selectively impacts the heme-bound diatomic ligands of CYP17 Biochemistry 53, 90- 100DOI: 10.1021/bi4014424

79 Duggal, R., Liu, Y., Gregory, M. C., Denisov, I. G., Kincaid, J. R., and Sligar, S. G. (2016)Evidence that cytochrome b5 acts as a redox donor in CYP17A1 mediated androgen synthesisBiochem. Biophys. Res. Commun. 477, 202-208DOI: 10.1016/j.bbrc.2016.06.043 
$\underline{80} \mathrm{Ibrahim}, \mathrm{M} ., \mathrm{Xu}, \mathrm{C}$. , and Spiro, T. G. (2006) Differential sensing of protein influences by NO and CO vibrations in heme adducts J. Am. Chem. Soc. 128, 16834-16845DOI: 10.1021/ja064859d

81 Ray, G. B., Li, X. Y., Ibers, J. A., Sessler, J. L., and Spiro, T. G. (1994) How far can proteins bend the FeCO unit? Distal polar and steric effects in heme proteins and models J. Am. Chem. Soc. 116, 162-176DOI: 10.1021/ja00080a019

82 Li, X. Y. and Spiro, T. G. (1988) Is bound carbonyl linear or bent in heme proteins? Evidence from resonance Raman and infrared spectroscopic data J. Am. Chem.

Soc. 110, 6024- 6033DOI: 10.1021/ja00226a017

83 Chartier, F. J. M., Blais, S. P., and Couture, M. (2006) A weak Fe-O bond in the oxygenated complex of the nitric-oxide synthase of Staphylococcus aureus J. Biol.

Chem. 281, 9953- 9962DOI: 10.1074/jbc.M513893200

84 Davydov, R., Satterlee, J. D., Fujii, H., Sauer-Masarwa, A., Busch, D. H., and Hoffman, B. M.(2003) A Superoxo-Ferrous State in a Reduced Oxy-Ferrous Hemoprotein and Model Compounds J. Am. Chem. Soc. 125, 16340-16346DOI: 10.1021/ja037037e

\section{Supporting Information}

The Supporting Information is available free of charge on the ACS Publications website at DOI: 10.1021/acs.biochem.7b00766.

- Additional methods, Table S1, Figure S1, and additional references (PDF)

- Pdf bi7b00766 si 001.pdf (361.66 kb) 


\section{Isolation and purification of CYP11A1 and Adrenodoxin}

In the first step, the external fat and connective tissue were removed from the tough, shiny exterior membrane (capsule) of the adrenal glands. Each adrenal gland typically weighted $\sim 15-30$ grams and was then processed as follows. The gland was carefully sliced, using a surgical scalpel, into two parts along the long axis, exposing the interior. The interior comprises yellowish central region, called the medulla, surrounded by a reddish brown major region called adrenal cortex. The adrenal cortex contains the targeted CYP11A1, as well as several other CYP isoforms, including CYP11B, as well as redox partners, the adrenodoxin ( $\mathrm{ddx}$ ) and adrenodoxin reductase (AdR). ${ }^{1}$ The medulla was removed using a scalpel and tweezers and discarded. The adrenal cortex matrix was carefully scraped off from the capsule and temporarily stored on an ice-cooled glass plate; this removal is most effectively performed by holding the capsule with a tweezers while scraping away the cortex. Having collected the cortex matrix from $\sim 20$ glands, the material is repeatedly sliced and chopped into a rough, slightly lumpy paste and suspended in 4 volumes of $0.25 \mathrm{M}$ sucrose solution containing $10 \mathrm{mM}$ phosphate $\mathrm{pH} 7.4,0.1 \mathrm{mM}$ ethylenediaminetetraacetic acid (EDTA) and $0.1 \mathrm{mM}$ dithiothreitol (DTT). This suspension was homogenized using a Potter Elvejhem (piston/tube) type homogenizer to yield a thick, smooth suspension, which was then centrifuged at $4{ }^{\circ} \mathrm{C} 500 \times \mathrm{xg}$ for 10 minutes to remove the unbroken cells and nuclei. The supernatant was then centrifuged again at $11,000 \times \mathrm{xg}$ for 30 minutes at $4{ }^{\circ} \mathrm{C}$ to yield a reddish solution and a brown pellet of mitochondria.

The mitochondrial pellets were re-suspended in $20 \mathrm{mM}$ phosphate buffer, $0.1 \mathrm{mM}$ EDTA, $0.1 \mathrm{mM}$ DTT. The mitochondrial suspension ( $50 \mathrm{~mL}$ portions) was placed into an ice bath and sonicated with a Branson Sonifier 450 probe type sonicator at a power setting of 3.0, forming a voluminous froth, but making sure to maintain the temperature of the suspension below $4{ }^{\circ} \mathrm{C}$. The solution was centrifuged for 1 hour at $100,000 \times$ g and the resulting sub-mitochondrial pellets were re-suspended in $100 \mathrm{mM}$ phosphate buffer, 0.1 mM EDTA, $0.1 \mathrm{mM}$ DTT to yield a protein concentration of $15 \mathrm{mg} / \mathrm{ml}$. Sodium cholate (10\%) was added to the solution of sub-mitochondrial suspension to yield a $1 \%$ cholate concentration and the sub-mitochondrial particles were extracted for 1 hour. The suspension was centrifuged for 1 hour at 100,000xg and the supernatant recovered. An ammonia sulfate fraction procedure was used to further purify the extracted proteins. ${ }^{2}$ In the first step, ammonium sulfate was added to bring its concentration to $30 \%$, with the resulting precipitate (containing CYP11B1) ${ }^{1}$ being discarded or stored, as desired. Then additional ammonium sulfate was added to the supernatant to bring its concentration to $45 \%$, at which point a precipitate containing the targeted CYP11A1 formed, which was then collected by centrifugation. The pellets were suspended in $100 \mathrm{mM}$ phosphate buffer containing $0.1 \mathrm{mM}$ EDTA and $0.1 \mathrm{mM}$ DTT. The CYP11A1 was isolated by chromatography using octyl sepharose column that was first washed with original buffer containing $0.03 \%$ cholate, followed by protein elution using the original buffer containing $0.3 \%$ cholate. The fractions with $R_{z}$ of $A_{390} / A_{280}$ larger than 0.6 were collected. The final $R_{z}$ value was $\sim 0.65$ after pooling all the fractions together. The yield of CYP11A 1 is about $25 \mathrm{mg}$ protein/500g glands.

The concentration of CYP11A1 was determined using UV-Vis absorption spectroscopy of ferrous-CO adducts and the reduced form as reference. The difference between the absorbance measured at $450 \mathrm{~nm}$ and $490 \mathrm{~nm}$ was used to calculate the concentration, based on the reported differential extinction coefficient of 91 $\mathrm{cm}^{-1} \mathrm{mM}^{-1}$. ${ }^{3}$ The concentration of Adx was calculated based on the extinction coefficient $11 \mathrm{~cm}^{-1} \mathrm{mM}^{-1}$ at 414 $\mathrm{nm} .^{3}$

\section{Enhancement of $v(\mathrm{Fe}-\mathrm{O})$ and $\mathrm{v}(\mathrm{O}-\mathrm{O})$ by different excitation lines}

The lack of the $\mathrm{v}(\mathrm{Fe}-\mathrm{O})$ mode enhancement in the CYP11A1 samples with 22R-OHCH substrate was unexpected, prompting further investigations. The oxy adducts of cytochromes P450 exhibit an electronic structure similar to that of ferric state; e.g., they possess a strong Soret band that arises from the $\pi$ to $\pi^{*}$ transition between Fe and porphyrin. In early studies, Soret excitation was used to study ferric $\mathrm{P} 450{ }^{4}$ and then this excitation was extended to studies of oxy samples of P450s. ${ }^{5-7}$ The Density functional theory (DFT)-based 
calculation on an iron porphine in its oxy complex was reported, ${ }^{8}$ showing that there are 16 electronic excitations corresponding to 38 electronic transitions from $280 \mathrm{~nm}$ to $471 \mathrm{~nm}$ for the fragment of S-Fe-O-O. It has been shown previously, that the oxy P450cam and its D251N mutant can be efficiently studied using $356 \mathrm{~nm}$ and $413 \mathrm{~nm}$ excitation lines. 5,9 Furthermore, it has been reported that the $v(0-0)$ mode of oxy P450cam can be detected using $420 \mathrm{~nm}$ and $442 \mathrm{~nm}$ excitation lines. ${ }^{6,10}$ The intensity of $\mathrm{v}(\mathrm{O}-\mathrm{O})$ mode of P450cam increases as excitation line increases from $356 \mathrm{~nm}, 413 \mathrm{~nm}$ and $420 \mathrm{~nm}$, and $441 \mathrm{~nm}$ while the intensity of $\mathrm{v}(\mathrm{Fe}-\mathrm{O})$ mode decreases from $356 \mathrm{~nm}$ to $413 \mathrm{~nm}$, with no $v(\mathrm{Fe}-\mathrm{O})$ being detected by using $420 \mathrm{~nm} .{ }^{5,6,9,10}$ The CYP11A1 samples containing 22R-OHCH substrate were measured employing the $356.4 \mathrm{~nm}, 413.1 \mathrm{~nm}, 415.4 \mathrm{~nm}$ and $441.6 \mathrm{~nm}$ excitation lines. Interestingly, while the $\mathrm{v}(\mathrm{O}-\mathrm{O})$ mode was relatively well enhanced with first three excitation lines, it was not observed with 441,6 nm excitation. Even though the $v(0-0)$ mode was strongly enhance for some excitation, the $v(\mathrm{Fe}-\mathrm{O})$ mode was not enhanced using any of these excitation lines. It is noted that the presence of glycerol contributes greatly to increased fluorescence background of these frozen samples. Such high background might obscure weak v(Fe-O) bands. In order to lower the fluorescence background, the CYP11A1 samples were prepared without the glycerol present. It has been noted that although the background was indeed significantly reduced, the $v(\mathrm{Fe}-\mathrm{O})$ mode was still not observed in the samples containing the second substrate.

The possibility of accidental photodissociation was eliminated by making $r R$ measurements of the CYP11A1 samples in the spectral region that includes the $v(\mathrm{Fe}-\mathrm{O})$ and $v(\mathrm{O}-\mathrm{O})$ modes simultaneously; e.g., $400-$ $1200 \mathrm{~cm}^{-1}$. While the $\mathrm{v}(\mathrm{O}-\mathrm{O})$ mode was served, the $\mathrm{v}(\mathrm{Fe}-\mathrm{O})$ mode was absent.

Table S1 The calculated high spin population (\%) in CYP11A1 in the presence of different substrates, without and with $\mathrm{Adx}$, in $100 \mathrm{mM}$ phosphate buffer containing $0.1 \mathrm{mM}$ EDTA and $0.1 \mathrm{mM}$ DTT.

\begin{tabular}{|l|l|l|}
\hline CYP11A1 bound to: & Adx & resonance Raman (\% HS) \\
\hline & - & 63 \\
\hline & + & 73 \\
\hline 22R-OHCH & - & 8 \\
\hline & + & 13 \\
\hline 20R,22R-DiOHCH & - & 76 \\
\hline & + & 82 \\
\hline
\end{tabular}




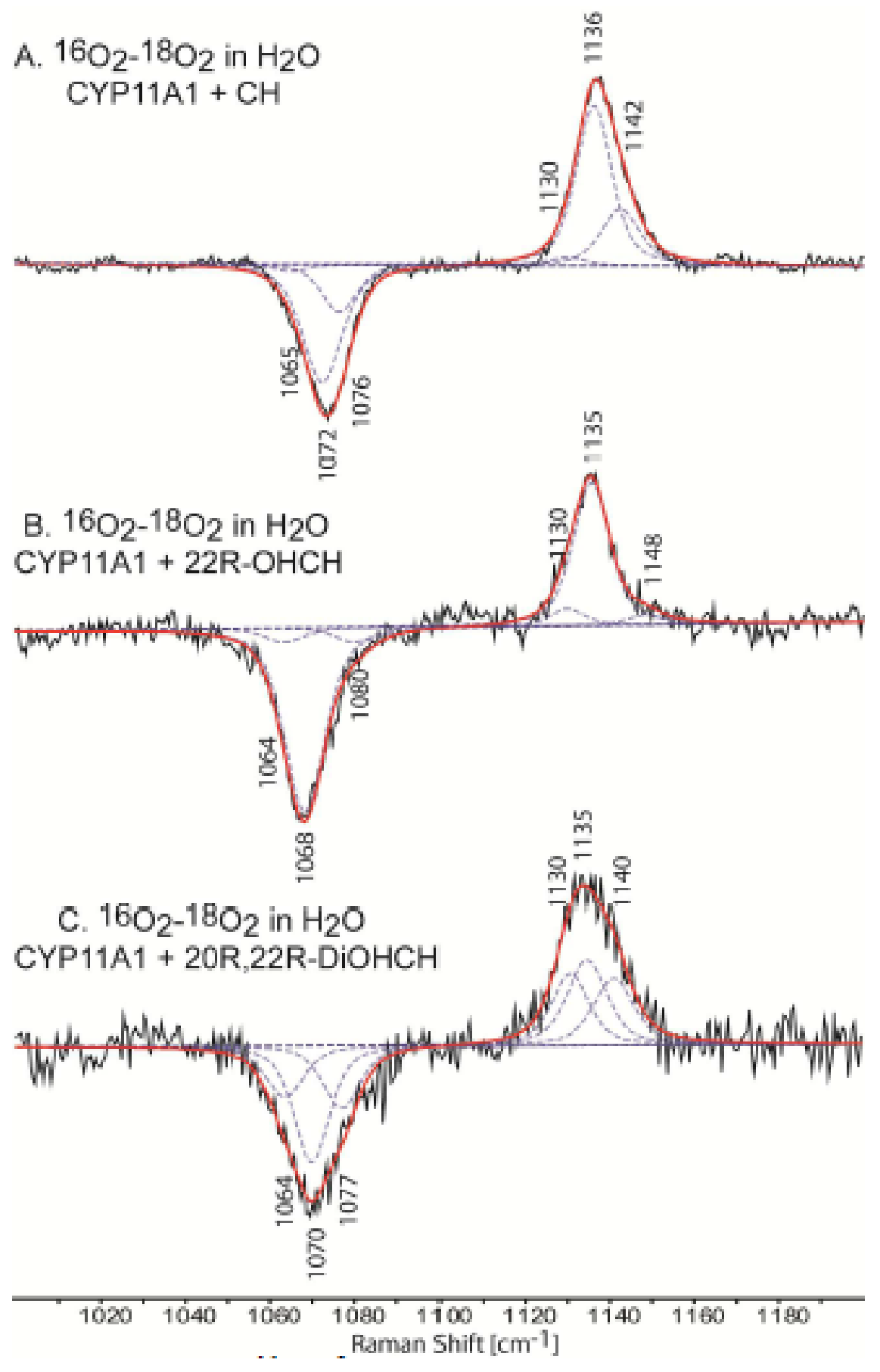

Figure S1. The deconvoluted ${ }^{16} \mathrm{O} 2-1^{8} \mathrm{O}_{2}$ difference traces in $\mathrm{H}_{2} \mathrm{O}$ buffer of oxy adducts of CYP11A1 containing CH (A), 22R-OH (B) and 20R,22R-DiOHCH (C). The traces were fitted using 50/50 \% Gaussian/Lorentzian functions with band width of $10.0 \mathrm{~cm}-1$ ( \pm 0.5 $\mathrm{cm}-1)$. It is noted that the deconvoluted data follow the same spectral pattern observed in the experimental traces; e.g., Figure 7 of the manuscript. 


\section{Reference}

1. Tsubaki, M., Ichikawa, Y., Fujimoto, Y., Yu, N., and Hori, H. (1990) Active Site of Bovine Adrenocortical Cytochrome P-45011 $\beta$ Studied by Resonance Raman and Electron Paramagnetic Resonance Spectroscopies : Distinction from Cytochrome P- 450scc. Biochemistry 29, 8805-8812.

2. Tuckey, R. C., and Stevenson, P. M. (1984) Properties of Bovine Luteal Cytochrome P450scc Incorporated into Artificial Phospholipid Vesicles. Int. J. Biochem 16, 497-503.

3. Headlam, M. J., and Tuckey, R. C. (2002) The effect of glycerol on cytochrome P450scc (CYP11A1) spin state, activity, and hydration. Arch. Biochem. Biophys 407, 95- 102.

4. Remba, R. D., Champion, P. M., Fitchen, D. B., Chiang, R., and Hager, L. P. (1979) Resonance Raman investigations of chloroperoxidase, horseradish peroxidase, and cytochrome $c$ using Soret band laser excitation. Biochemistry 18, 2280-2290.

5. Macdonald, I. D. G., Sligar, S. G., Christian, J. F., Unno, M., and Champion, P. M. (1999) Identification of the Fe-O-O Bending Mode in Oxycytochrome P450cam by Resonance Raman Spectroscopy. J. Am. Chem. Soc. 121, 376-380.

6. Hu, S., Schneider, A. J., and Kincaid, J. R. (1991) Resonance raman studies of oxycytochrome P450cam: effect of substrate structure on v(O-O) and v(Fe-O). J. Am. Chem. Soc. 113, 4815-4822.

7. Gregory, M., Mak, P. J., Sligar, S. G., and Kincaid, J. R. (2013) Differential hydrogen bonding in human CYP17 dictates hydroxylation versus lyase chemistry. Angew. Chem. Int. Ed. Engl. 52, 5342-5345.

8. Harris, D., Loew, G., and Waskell, L. (1998) Structure and Spectra of Ferrous Dioxygen and Reduced Ferrous Dioxygen Model Cytochrome P450 120, 4308-4318.

9. Complex, P., Sjodin, T., Christian, J. F., Macdonald, I. D. G., Davydov, R., Unno, M., Sligar, S. G., Hoffman, B. M., and Champion, P. M. (2001) Resonance Raman and EPR Investigations of the D251N Oxycytochrome P450 cam/Putidaredoxin Complex. Biochemistry 4, 6852-6859.

10. Bangcharoenpaurpong, O., Rizos, A. K., Champion, P. M., Jollie, D., and Sligar, S. G. (1986) Resonance Raman detection of bound dioxygen in cytochrome P-450cam. J Biol Chem 261, 8089-8092. 